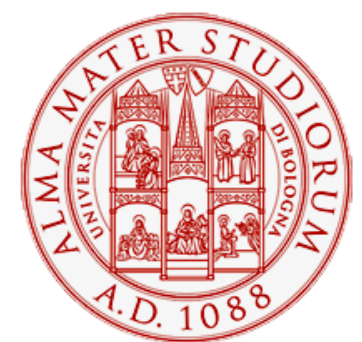

Alma Mater Studiorum - Università di Bologna DEPARTMENT OF ECONOMICS

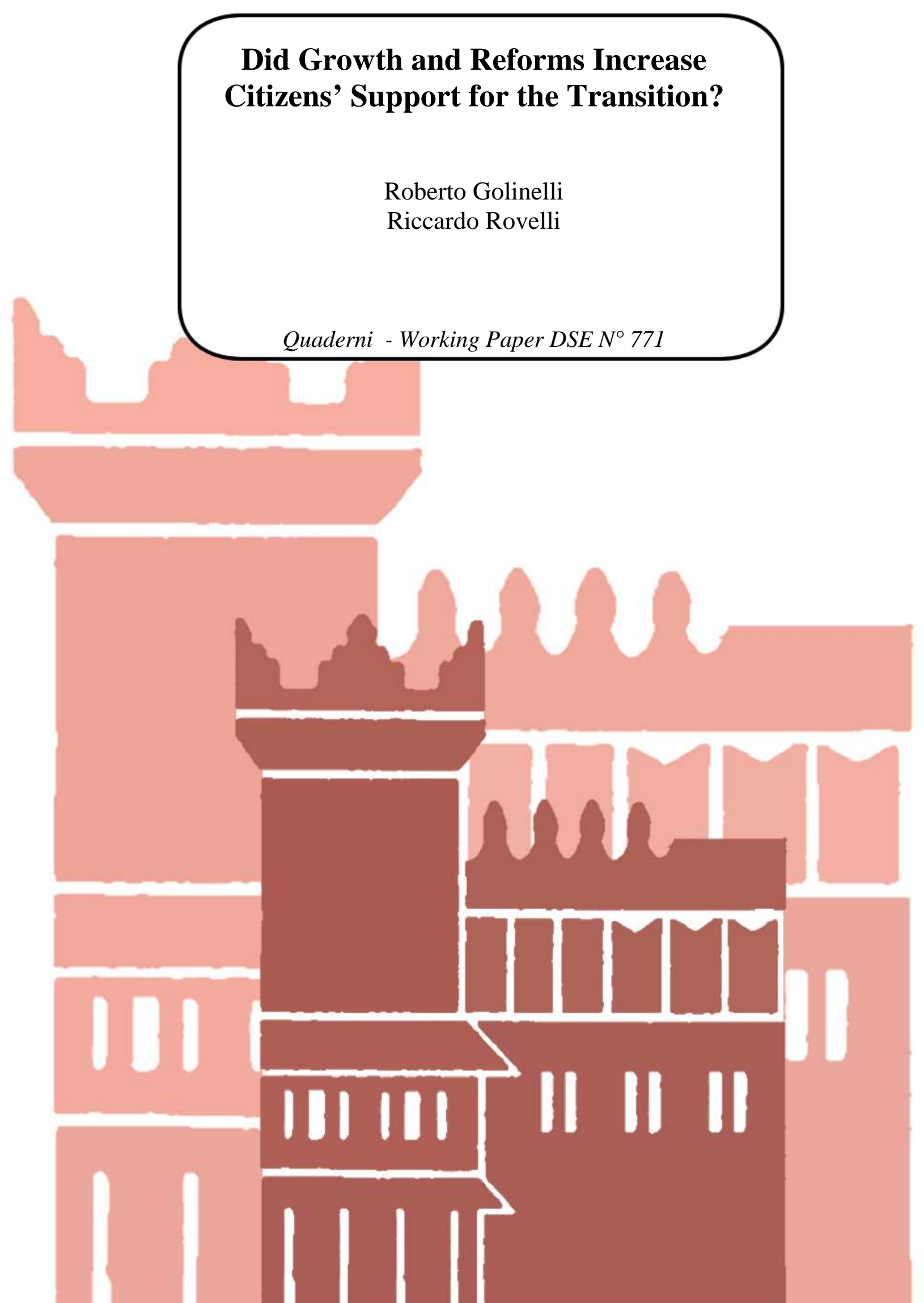




\title{
Did Growth and Reforms Increase Citizens' Support for the Transition?
}

\author{
Roberto Golinelli ${ }^{*}$ and Riccardo Rovelli ${ }^{* *}, 1$
}

4 July 2011

\begin{abstract}
How did post-communist transformations affect people's perceptions of their economic and political systems? We model a pseudo-panel with 89 country-year clusters, based on 13 countries observed between 1991 and 2004, to identify the macro and institutional drivers of the public opinion. Our main findings are: (i) When the economy is growing, on average people appreciate more extensive reforms; they dislike unbalanced reforms. (ii) Worsening of income distribution and higher inflation interact with an increasing share of the private sector in aggravating nostalgia for the past regime. (iii) Cross-country differences in the attitudes towards the present and future (both in the economic and political dimensions) are largely explained by differences in the institutional indicators for the rule of law and corruption. (iv) Cross-country differences in the extent of nostalgia towards the past are mainly related to differences in the deterioration of standards of living.
\end{abstract}

Keywords: Political economy; Post-Communist transition; Economic reforms; Economic performance; Support for reforms; Public opinion.

JEL Classification: 011; 057; P2; P36; P52.

* Dipartimento di Scienze Economiche, Università di Bologna. E-mail: roberto.golinelli@unibo.it

** Dipartimento di Scienze Economiche, Università di Bologna and IZA, Bonn. E-mail: riccardo.rovelli@unibo.it

1 We thank participants at an IZA Topic Week on The Political Economy of Labor Market Reform for useful comments. We are grateful to Irina Denisova and especially to Gaetano D'Adamo and Karsten Staehr for detailed comments and suggestions. We acknowledge use of data from the New Europe Barometer surveys, which were kindly made available to us by IZA, and coded by Anzelika Zaiceva. 


\section{Introduction}

The fall of the Berlin Wall in 1989 brought about a new world of hope and opportunities for peoples and countries that engaged along the path of the post-communist transformation. Many postcommunist countries, especially those nearer to the Eastern boundaries of the European Union, ${ }^{2}$ soon adopted the institutions of democracy and agreed that the setting up of a market economy would be an essential ingredient of it. ${ }^{3}$ People gained at the same time freedom of thought, speech and action, and the opportunity to grow rich. Under these circumstances, it might have been reasonable to expect that the new, post-communist citizens should just work hard and be happy. Instead, the transformation proved to be a bumpier road than it had been envisaged. People soon began to voice their doubts and concerns, rather than an overwhelming satisfaction, and those doubts have not yet faded away. In fact, political scientists had warned not to expect that everything would flow smoothly during the transformation. "Because a communist regime had a non-market command economy run by bureaucrats, post-communist regimes must create market institutions at the same time as democratic institutions. The simultaneous transformation of polity and economy, and the potentially explosive interaction between the two, makes outcomes uncertain. ... The practice of governance in a newly created democracy is a process of trial and error, a search across a terrain for which there is no map. ... Change can lead in more than one direction. Only a 'democratic bolshevik' would believe that introducing democratic institutions in place of a communist regime could immediately produce a stable democracy." (Rose, Mischler and Haerpfer, 1998, p.7).

In this respect we can see at least two different patterns of transformation. In those countries that were closer to the EU, democracy has proved remarkably stable, while setting up ex novo a market economy has proved difficult, and many citizens have been disappointed in the process. On the other hand, in countries belonging to the Commonwealth of Independent States (CIS) uncertainty has been more fundamentally centered around the characteristics of the political process. Overall, according to a broad survey conducted in 2007 by the EBRD, almost half of the people interviewed disagreed (and only $35 \%$ agreed) with the statement that the economic situation in their country today is better than around 1989, with similar numbers corresponding to the political situation (EBRD, 2007a; see also Guriev and Zhuravskaya, 2009). But why is that? Of course, it may be possible to interpret these (and other findings of a similar tone) as only signaling the end of a "honeymoon effect", or as an exercise in the rhetoric of self-deprecation. Or, alternatively, they might point to a real source of discontent - in which case it becomes interesting to find out more about its causes.

2 Until 1989 the EU (then the European Community) had only 12 members. Austria, Finland and Sweden joined only in 1995, after the fall of the Wall.

3 Note that the opposite would not be necessarily true, as a market economy does not always require democracy. Staher (2006) provides an empirical confirmation of this presumption. 
One way to analyze discontent, or disillusionment, as the consequence of a rational (re)assessment, is to link it to the evidence of unfulfilled or disappointed expectations, which in turn may have been nurtured by the experiences of individual failures and defeats. In fact, personal disappointment may become a relevant political factor, as it might explain how a majority that initially supported reforms could turn into a majority that opposes their continuation or even demands their reversal. ${ }^{4} \mathrm{~A}$ search for evidence in favor of such explanations motivates our research.

More generally, the research questions which we address are related to how people react to the experience of a process of political and economic transformations that affect their current welfare and their expectations for the future. Some of these questions are naturally addressed in a comparative framework:

- How do judgments about the past and the present and expectations for the future differ across post-communist countries?

- Are these differences related to the different paths of reforms and transformations across countries?

These broad questions lead us to pose more specific ones, that might be addressed in parallel for all countries:

- Are assessments about the past, present and future affected by the same or by different groups of variables?

- Do individual evaluations about the economic system move in parallel to those for the political system, or is each sphere of judgments related to different groups of observable variables?

- How do these assessments change as reforms are implemented and the economy grows?

To address these questions, we will focus on the determinants of the aggregate (median) assessments prevailing in each country at a particular time. More specifically, our study is based on the aggregate analysis of individual micro data. Thus, although it is based on the same dataset used in the related micro analysis described in Rovelli and Zaiceva (2011), this paper has a distinct macro focus. (See below for more details on the dataset.)

The theoretical motivation for this paper is related to a long lasting debate. For our purposes, we take as a first reference point the paper by Aghion and Blanchard (1994), which identified theoreticallyrelevant stylized facts that later characterized most political economy (PE) analyses of the postcommunist transformation. In particular they observed that post-communist reforms needed to generate a substantial shift of economic activities from the state to the private sector. If this shift is

4 This observation is related to Fernandez and Rodrik (1991), whose central idea was in turn foreshadowed by Machiavelli's (1513) remarks on the difficulty and danger of "an attempt to introduce a new order of things in any state". From these contributions we retain the idea that, once introduced, reforms may lose popular support, as the ex post distribution of gains and losses may no longer generate a democratic majority of supporters' 
either too fast or too slow, as it may often be the case, then it might run out of steam as it does not generate a sufficient amount of resources to support itself. ${ }^{5}$ Although Aghion and Blanchard's is not a PE paper, it has nevertheless opened the way for several studies in that vein. These were based on recognizing that different configurations of post-communist reforms would essentially generate different patterns of winners and losers, and thus might be alternatively chosen, depending on alternative configurations of the political process.

The range and depth of post-communist transformations has naturally attracted a large amount of research. Common to all the transition economies was the need to restructure internal production, to open up to new patterns of international trade, and to reallocate labor across regions, sectors and firms (Campos and Coricelli, 2002). The necessary reforms, which included privatization, trade liberalization and macroeconomic stabilization, took place in a situation of institutional change, where many institutions that had provided social insurance under the previous socialist system had collapsed, and other institutions, which were needed to ensure the well functioning of transitional reforms, such as taxation or banking, had to be introduced on entirely new grounds.

As observed by Boeri and Terrell (2002), the extent to which labor reallocation has taken place within a country is a strong indicator of progress made along the path of transitional reforms. In this respect, the adjustment patterns of the output and labor markets differed substantially between the Central and Eastern European (CEE) and CIS countries. With a few exceptions, most CEE countries experienced a U-shaped pattern of GDP, a large fall in employment early in the 1990s and some decline in labor productivity leading to rapid structural change but also to high unemployment (with the exception of the Czech Republic), much of which was long term. In contrast, the CIS countries typically faced an L-shaped pattern of GDP during the 1990s and a relatively modest decline in employment with limited sectoral reallocations of labor. Here, however, there was a more pronounced deterioration in labor productivity and of real wages, as well as a significantly larger increase in inequality than in the CEE countries (Boeri and Terrell, 2002; Svejnar, 2002; Milanovic and Ersado, 2008). Overall, while the labor market adjustment process took the form of larger declines in employment in the CEE countries, it typically occurred through real wage declines in the CIS. And only as transition progressed, unemployment began to increase gradually also in the CIS countries (Svejnar, 2002).

In this paper we shall treat these decisions about adoption, design and sequence of reforms as factors affecting how the public opinion assessed the process of transition. Thus, our empirical analysis is related to two strands of research: (i) the earlier studies using macro-economic variables to explain voting behavior (Fidrmuc, 2000), support for the market economy (Hayo, 2004; Kim and Pirttilä, 2006)

5 In particular, if the rate of labor shedding by the state sector is too fast it might actually (i) reduce the speed of restructuring in state firms as workers resist managers' attempts to restructure, (ii) reduce the level of aggregate demand, and also (iii) hinder the speed of job creation in the emerging private sector. This latter result will come about to the extent that higher unemployment translates into higher taxes (and less profits) for newly created firms, which as the only profitable and hence taxable units of the economy bear the entire costs of the unemployment benefits. 
or "capitalism aversion" (Landier et al., 2008); (ii) the more recent cross-country studies based on micro data which have sought to analyze the "unhappiness in transition" (Guriev and Zhuravskaya, 2009; Easterlin, 2009), the determinants of public dislike for privatization policies (Denisova et al., 2007), the evolution of support for both economic and political changes (Rovelli and Zaiceva, 2011). This last paper, in a study of 14 countries from 1991 to 2004, provides a systematic characterization of winners and losers, and a comparison of individual attitudes towards the post-communist transformation across space and time. One of the main findings is that the older, less skilled, unemployed and poorer people, and also those living in the CIS countries, were less likely to support the changes in the economic and political system that were brought by the transition. Also, for the CIS countries, preferences for a greater role of the state in the economy and for more secure jobs, and subjective lack of trust in political institutions, together with the lower quality of political institutions (as measured by the governance indicators) contribute to a negative attitude towards economic reforms. In relation to this, the data also show that a negative opinion about the present is often associated we with a state of "nostalgia" about the communist regime. We briefly comment about this in the next section.

Our main objective is to explain why apparently similar policies adopted across different countries generated different levels of popular support. In this respect we follow Guriev and Zhuravskaya (2009) and Rovelli and Zaiceva (2011) although, as anticipated above, our approach to the data is different, as we concentrate here only on two data dimensions (time and space), neglecting variability across individuals. This allows us to concentrate on the macro, institutional and policy influences on the public opinion. One aspect which we highlight - and which will be supported by our results - is that each reform should not be taken and valued by itself. In many instances, a reform is in fact part of package, bundled together with other potentially complementary reforms. Moreover, each reform or package interacts with the effects of previous and subsequent reforms, and of old and new institutions. This idea of reform complementarity has been pursued empirically by Staehr (2005) for transition countries and, in a broader context, by Braga de Macedo and Oliveira Martins (2008), who study the impact of complementarities on the growth rate of transition economies. Our hypothesis is that the concept of complementarity between reforms should also apply to their perceived costs and benefits, so that the approval or disapproval rate of each reform may also depend on which other reforms are associated with it. Our research strategy then follows from the formulation of this hypothesis: thus in the first part of the paper we examine synthetic measures of people's judgments about the transition process, and in the second part we model the relations between these judgments and variables measuring the state of the economy, the pattern of reforms and the quality of institutions. One limitation of our approach is that we concentrate on measures of the median or average public opinion, thus neglecting the dispersion or variability of people's opinions. We plan to take measures of the dispersion of the public opinion explicitly into account in a related research.

The paper is organized as follows. In Section 2 we describe the data and in Section 3 we explain how individual responses can be usefully synthesized in two variables or macro factors: FM1, which 
synthesizes the median individual response about the present and the future of the economic and political systems; FM2, which synthesizes responses relative to the past economic and political systems. In section 4 we introduce and motivate our framework for the empirical analysis of these two macro factors and in section 5 we present estimates of a corresponding macro pseudo-panel model. We find that the state of advancement of the reform process and macroeconomic performance are important determinants of F1, while other macro variables, that measure the impact of transition on different social groups, are the main determinants of F2. In Section 6 we reparameterize the model to emphasize the differences across countries. We find these differences to be unrelated to variables that explain the evolution of responses within each country; on the contrary, they are strongly related to relatively time-invariant cross-county institutional and economic differences. Section 7 sums up and concludes.

\section{The data: The NEB surveys and the six basic response variables}

As we anticipated in the Introduction, our research is part of an ongoing project, devoted to the analysis of a large data set, comprising several thousands of interviews, conducted in 14 postcommunist countries from 1991 to 2004. Interviews were collected over time and published in separate datasets by the Centre for the Study of Public Policy (CSPP) at the University of Aberdeen (see below). Interviewees were asked to express their opinions on several aspects of the economic and political life. The original datasets have been coded into a single dataset, as reported in Rovelli and Zaiceva (2009), who also provide a first detailed econometric analysis of the responses. In this paper we propose a complementary, aggregative approach to the same issues. Rather than focusing on and characterizing differences between individual responses, here we focus on the "macro" drivers of individual attitudes. Hence our analysis explores how the median voter (the median interviewed person) did react to the changing performance of the economy and to the transitional reforms.

The data. Median opinion data are aggregated from micro data, originated from a number of large surveys, consistently conducted over time by the Centre for the Study of Public Policy (CSPP) at the University of Aberdeen and the Paul Lazarsfeld Society, Vienna. Each surveys is based on a representative sample of the population in each of 14 transition countries. They are available from CSPP under the separate names of New Europe Barometer, New Russia Barometer and New Baltic Barometer; each Barometer contains between 4 and 7 surveys ("waves") conducted in each country between 1991 and 2004. Ten countries in the sample became members of the EU in the 2004 or 2007 enlargements (Bulgaria, Czech Republic, Estonia, Hungary, Latvia, Lithuania, Poland, Romania, Slovakia and Slovenia); Croatia is currently a EU candidate; Belarus, Russia and Ukraine are members of the CIS. Each survey contains a large number of common questions, in particular questions on individual opinions about the past and present economic and political systems. Hence the set of available surveys constitutes a unique dataset that allows meaningful cross-country comparisons from 
1991 until 2004. In particular we use a single dataset based on the separate CSPP files, as extensively explained in Rovelli and Zaiceva (2009). See also the Data Appendix .

In conjunction with these survey data we also use macro-economic and institutional variables, in particular to measure the spread and intensity of transitional reforms. Also these data are described in the Data Appendix.

The six basic responses. In the New Europe Barometer (NEB) surveys, individuals from fourteen countries are asked questions on how they think the economic and the political systems work in their countries. Distinct questions are asked for the past (defined as the former socialist or communist regime), the present and the future ("in five years time"). Table 1 synthesizes the phrasing of the six questions, and reports the corresponding names of the coded answers.

\section{Table 1 here}

Each response to these questions is measured in three dimensions, which refer to different individuals (i), located in different countries $(c)$ at different points in time ( $t$ ). Hence each observation is characterized as $\mathrm{y}_{\mathrm{i}, \mathrm{c}, \mathrm{t}}$. Note that time is not observed on a regular annual base.

\section{Table 2 here}

In Table 2 we report the total number of questionnaires obtained for each country and year. Overall there are 89 country-year cells. 1993 and 1995 are the only years in which all countries were surveyed, and then again in 2004, except for Croatia. These three (out of nine) years cover almost half of the whole sample (102,368 observations). Each country covers between 5 and 7 percent of the sample, with the exceptions of Russia (which by design had a sample size almost twice that of the other countries) and Croatia (with only four waves of interviews).

\section{Table 3 here}

In Table 3 we report descriptive statistics of the six basic responses. Out of a total of 102,368 interviews, the share of non-responses varies between $5-15 \%$ of the interviews. Non responses are more frequent for the two questions about the future. We were surprised to observe that the mean response to PRESEC is negative, while that to PASTEC is positive. On average, people seem more optimist about the future than they are satisfied about the present; also the past is generally rated better than the present. This evidence is perhaps surprising, but in fact it a common finding, also in other contexts. As Munro (2006) observes, "the phenomenon of widespread nostalgia has been noted in scholarly circles in Russia ... and amongst policy-makers in the United States, where it has even been seen as cause for concern because it implies low potential for a democratic breakthrough". And also "Russia is not unique [among former communist countries], in having high levels of nostalgia. The 2004 New Europe Barometer survey showed that an average of 54 per cent of citizens of the eight post-Communist new EU members gave the old regime a positive assessment. The most nostalgic new EU country was Slovenia with 70 percent giving the Yugoslav regime founded by Tito a positive rating and the least was the Czech Republic, where Soviet troops enforced the Brezhnev doctrine at 
gunpoint: there 31 per cent were nostalgic." ${ }^{6}$ Even if nostalgia is not directly "action oriented", it is nevertheless a worrying phenomenon. Moreover, the implications of nostalgia for economic analysis and for economic policy making are still to be explored. In this respect, it may be helpful to be reminded that "Uncertainty (unsureness) is a deep property of decentralized systems in which a myriad of independent agents make decisions ... Uncertainty about what the outcomes will be follows from the uncertainty with which agents hold the model that guides their actions"(Minsky, 1996). In this vein of thought, it may be true that, while struggling to "learn", that is to overcome uncertainty about the current (and evolving) model of society and the economy, some people - and especially those who think they are likely to be among the "losers" in the new environment, resort to nostalgia. And this may be occurring even more often, if the previous regime had engendered the expectation of being entitled to certain welfare benefits, which the losers then internalize as their "moral property right" (Gächter and Riedl, 2002).

Turning to the statistics presented in Table 3, we also observe that, while the sample means of the six variables are quite different, their standard deviations are remarkably close to each other. To understand the sources of heterogeneity by country and over time, we first computed the means and standard deviations for each of the 89 country-year clusters counted in Table 2; we then decomposed their variability between countries and over time in three parts: one share is explained by differences in country means or standard deviations ("country effect"), a second share by a time-varying (macro) drift common to all countries ("time effect"), while the residual share captures idiosyncratic factors.

For the means of individual responses, the country effect is always the main determinant of the heterogeneity in the responses about the past and the present, while idiosyncratic effects account for the largest shares of variability in those about the future. The same is true for the standard deviations, although the residual effects are in general larger for all the six variables. The drifts over time of the means and standard deviations of the individual responses are not particularly relevant. Since the heterogeneity of responses across countries is quite large and tends to dominate the overall variability, it will be important to account for this dimension in our analysis (see Section 6). On the other hand, we can exploit the strong correlation between the six basic response variables within each country-year: by doing so, we avoid the difficult task of modeling the variability of the six variables of interest in fourteen countries along only a few years. The simple correlation matrix between these variables is reported in Table 4, from which we draw two conclusions: first, the two responses concerning evaluation of the past regimes are strongly correlated with each other, but not with the other four variables, and vice versa the four response variables concerning the present and the future are strongly correlated with each other, and not with those concerning the past: in short,

${ }^{6}$ Munro (2006) defines nostalgia "as a positive view of the past regime, based on a holistic evaluation of its faults and merits. It should be distinguished from reaction--a desire to return to the status quo ante. In the Russian context this means returning to the Communist regime, or to a feasible reincarnation of it. Reaction is a more extreme position than nostalgia, and it is also more "action-oriented." 
the block of the two responses about the past does not significantly covariate with the block of the four responses about the present and future. We checked the robustness of this finding across the 89 country-year clusters (see Figures 1 and 2). Figure 1 plots the nine correlation coefficients in which at least one of the two variables is either PASTEC Or PASTPOL (corresponding to the first two columns of the correlation matrix in Table 4), and Figure 2 plots only the correlations of responses concerning the present and/or the future (corresponding to the last four columns of Table 4). Results are strikingly clear, with rare exceptions: visual inspection of the two Figures shows that the correlation structure which emerges from Table 4 is remarkably stable both within each country and over time: the only set of coefficients that are clearly different from zero in Figure 1 is that which involves the correlation between PASTEC and PASTPOL, and on the contrary all the blocks in Figure 2 report (with minor exceptions) non-zero coefficients between the responses on the present and the future. This in turn suggests that we may use statistical methods to reduce the dimensionality of the six groups of individual responses, as we describe in the next section.

Table 4 \& Figures 1 and 2 here

\section{Two summary measures of individual responses}

One crucial finding reported in the previous section is that individual evaluations of the economic and the political system tend to be very closely related with each other, for each time horizon(see the correlations reported in Table 4 and in Figures 1 and 2). This overlap of responses is quite surprising, and we believe that it may be due to the fairly general way in which the corresponding questions have been phrased, rather than to the inability of the interviewees to distinguish in principle between the two spheres. In any case, we will not attempt to distinguish between these two dimensions in this paper, and we shall leave this task to further research.

On the other hand, we can use the information provided by each set of responses (on the economy and on the polity) to reinforce the information from the other. Accordingly, and following the suggestion of Anderson (1974, p. 272-273), our empirical analysis will focus on those combinations of responses which concentrate the largest variability of the individual responses. Therefore we study the differences in the individual responses on the political and economic systems by using appropriate orthogonal linear combinations, such as the principal components of the individual responses. ${ }^{7}$

An additional reason to "compact" the individual responses in just a few variables is also suggested by the characteristics of the empirical analysis that we will conduct. In this respect, our aim it to identify

\footnotetext{
${ }^{7}$ The broad idea of factor analysis is to obtain estimates of latent variables which lay behind the individual responses, and which can be measured only by using the observed responses.
} 
the macro and institutional determinants ("drivers") of the individual judgments. To this purpose, we will naturally focus on what distinguishes each country-year cluster from the others. This in turn requires to conduct a dynamic analysis, which however will be constrained in several dimensions: gaps in the time series; non-observable explanatory variables; collinearity between includable variables. Given the limited sample size, estimated models may be negatively affected by data anomalies such as outliers and structural breaks. With potentially up to six dependent variables, the usual collinearity to be found in many sets of socio-economic variables will be even more pervasive, as we might find ourselves plagued by a sort of "double collinearity", affecting both sets of dependent and explanatory variables. To reduce the consequences of this, it is helpful to summarize the dependent variables on the basis of their underlying statistical factors. In particular two features of factor analysis may help to contain the damages from collinearity: (i) factors are orthogonal to each other by construction; (ii) within each factor, the statistical averaging of responses dampens other data anomalies. In short, we believe that the loss of information coming from the aggregation of responses will be overcome by the advantages of data aggregation mentioned above. On the other hand, we will also perform several ex post checks and tests of the appropriateness of this approach.

3.1 - Micro factors. We first introduce formally the process of data aggregation. Let $\mathbf{X}=$ (PASTEC, PRESEC, FUTEC, PASTPOL, PRESPOL, FUTPOL)' be a matrix where the questions are in different rows, and the observations (answers) are in columns (each individual answer refers to a country at a given point in time). ${ }^{8}$ Define as $\mathbf{x}_{\mathbf{i} \boldsymbol{t}}$ the vector of $\mathbf{p}$ standardized responses (in our case $\mathbf{p}=\mathbf{6}$ ) by the $\mathbf{i}$-th individual in country $\mathbf{c}$ at time $\mathbf{t}$. We can express $\mathbf{x}_{\mathbf{i} \mathbf{c}}$ as a linear function of $\mathbf{k}$ latent factors:

$$
x_{i c t}=\Lambda_{c} f_{i c t}+\varepsilon_{i c t}, \quad \text { for } c=1, \ldots, 14
$$

where $\Lambda_{c}$ is a country-specific $\mathbf{p} \times \mathbf{k}$ matrix of factor loadings $(\mathbf{k}<\mathbf{p}), \mathbf{f}_{\mathrm{ct} \boldsymbol{i}}$ is the $\mathbf{k} \times \mathbf{1}$ vector of orthogonal latent factor scores (i.e. the common factors), and $\boldsymbol{\varepsilon}_{\mathrm{c} t \mathrm{i}}$ is a $\mathbf{p}$-vector of uncorrelated idiosyncratic disturbances, i.e. $\mathbf{p}$ judgment-specific factors assumed uncorrelated with the common factors $\mathbf{f}$.

Although principal components and factor analysis are different multivariate methods, ${ }^{9}$ principal components can be seen as one of the alternative approaches to estimate the factor loadings matrix $\Lambda_{c}$ and to extract factor scores that, in large samples and/or with communality (i.e. the sum of the squared factor loadings) close to one, should be very similar to those extracted with genuine factor analysis approaches.

\footnotetext{
${ }^{8}$ Since the second moments of the variables depend on their scale, it is customary to first standardize by country each variable in $\mathbf{X}$ to have mean zero and standard deviation one within each country.

${ }^{9}$ In order to reconstruct the six variables of interest, factor analysis requires to specify the model of equation (10) with the introduction of stochastic disturbances, while principal components analysis assumes that there are no disturbance terms, and thus it can be considered a sort of deterministic factor analysis.
} 
In order to assess whether the similarities of the scores imply the robustness of the findings of this paper to the use of alternative approaches, we extracted factors by using three main extractors: principal components factoring, principal factoring, and maximum likelihood factoring. In doing that, we always applied orthogonal varimax rotations to the loadings matrix in order to obtain a parsimonious and more interpretable representation of $\Lambda_{c}$, i.e. with few large loadings and as many as possible near-zero loadings.

In order to estimate the number of latent factors at the level of each country, Table 5 reports, along six columns, the ordered eigenvalues $\lambda_{\mathbf{j}}(\mathbf{j}=1,2, \ldots, 6)$ of the empirical covariance matrix of the six standardized response variables. The structure of the results by country is remarkably similar: following the Kaiser-Guttman's "eigenvalue greater than one" rule, $^{10}$ we find that $\mathbf{k}=\mathbf{2}$ for all countries. For this reason, in the last column of Table 5 we report the cumulative proportion of the overall variation explained by the first two principal components (variation "share" for $k=2$ ), which is remarkably high, always in the $66-75 \%$ range.

\section{Table 5 here}

In the following, we shall use the two factors scores by country, henceforth $\mathbf{f}_{\mathbf{c}} \mathbf{t} \mathbf{i}$ and $\mathbf{f} \mathbf{2}_{\mathbf{c}} \mathbf{t} \mathbf{i}$, extracted with the principal components factoring. In general, all the results of this paper are robust to the use of the other two extraction techniques, principal and maximum likelihood factoring. ${ }^{11}$

In order to summarize the meaning of $\mathbf{f} \mathbf{1}_{\mathrm{c} t} \mathbf{i}$ and $\mathbf{f} \mathbf{2}_{\mathrm{c} t \mathbf{i}}$, we can rely on $\mathrm{R}^{2}$ from regressions at the country level of each response variable against one factor at a time (either $\mathbf{f} \mathbf{1}_{\mathrm{cti}}$ or $\mathbf{f} \mathbf{2}_{\mathrm{cti}} \mathbf{i}$ ); the higher is $R^{2}$ of each regression, the most relevant is that factor to explain the response variable. Notice that this measure contains the same information as the specific factor loading. ${ }^{12}$

Figure 3 shows the map of the $R^{2}$ of 168 regressions ( 2 factors times 6 response variables times 14 countries), sub-divided into six panels (one for each response variable) ${ }^{13}$; each panel reports along the $y$-axis the $R^{2}$ of the country-level regressions of a response variable against $\mathbf{f} \mathbf{1}_{c t i}$, and along the $x$-axis the $R^{2}$ of the regressions against $\mathbf{f} \mathbf{2}_{c t i}$.

Figure 3 here

\footnotetext{
${ }^{10}$ It can be shown that components with eigenvalues greater than one embody variances greater than the average.

${ }^{11}$ All unreported are available upon request from the authors, together with the corresponding procedures to implement them.

12 In fact, when regression procedures are used to estimate the six correlations of each factor with either response variable, it can be shown that $\mathrm{R}^{2}$ of these regressions are equal to the squared of the corresponding factor loadings. Further, the sum of the two $\mathrm{R}^{2}$ for the two response variables is equal to their communality, as the two corresponding factor scores are orthogonal.

${ }^{13}$ In the first (second) row of plots there are the variables referring to the economic (political) situation, the three columns of plots are ordered from left to right by the timing of the question: past, present and future.
} 
A strong, consistent pattern emerges from all these panels. For those in the first column, the responses about the past (PASTEC and PASTPOL) are strongly related to $\mathbf{f} \mathbf{2}_{\mathbf{c} t \mathrm{i}}$, with an $\mathrm{R}^{2}$ on the $\mathrm{x}$-axis of about 0.80 , while they are almost unrelated to $\mathbf{f} \mathbf{1}_{\mathbf{c}} \mathbf{t} \mathbf{i}$, with $R^{2}$ on the $y$-axis always close to zero. Symmetrically in the other four panels, the responses about the present or future (PRESEC and PRESPOL; FUTEC and FUTPOL) exhibit the opposite pattern, that is a very strong relation with $\mathbf{f 1}_{\mathbf{c t} \mathbf{i}}$ and almost no relation with $\mathbf{f} \mathbf{2}_{\mathrm{ct} i}$.

Accordingly, we suggest that the two factors can be respectively interpreted as:

$\mathbf{f 1}_{\mathrm{ct} \boldsymbol{i}}$ summarizes individual responses about the present and the future, in both the economic and political dimensions. We shall refer to this as the "forward factor".

$\mathbf{f 2}_{\mathrm{ct} \mathrm{i}}$ summarizes individual responses about the past, in both the economic and political dimensions. We shall refer to this as the "backward factor".

Given the assumption that $\Lambda_{\mathbf{c}}$ is fixed over time, $\mathbf{f} \mathbf{1}_{\mathrm{ct} \mathrm{i}}$ and $\mathbf{f} \mathbf{2}_{\mathrm{ct}} \mathrm{i}$ are extracted by putting together all surveys for the same country. Therefore, within each country, they (a) have mean zero and standard deviation one, and (b) are uncorrelated with one another.

These features are relevant for our study. First, as we shall explain below, we will focus on these two factors as the dependent variables at the center of our analysis. Second, by focusing on how the country averages of each country change from year to year (around the full-sample mean of zero) we may obtain a preliminary information about how each country-factor changes through time. Third, as the two factors are uncorrelated with each other, we may map up to two interpretable summary dimensions for the responses of each individual, which are distinguishable in reference to the time horizon (forward vs. backward) but not to their "object" (such as economy versus policy or ideology). Fourth, since the two factors are uncorrelated, we expect that the set of potentially explanatory variables relevant to the first factor will include variables not relevant to the second factor, and vice versa.

3.2 - Macro factors. We now proceed to define the macro factors, which aggregate the individual factors in the country dimension. We could alternatively define them, for each country and time, as the unconditional means or medians of the individual factors $\mathbf{f} \mathbf{1}_{\mathbf{c} t \boldsymbol{i}}$ and $\mathbf{f} \mathbf{2}_{\mathbf{c}} \mathbf{t}$. We first compute the country-year means $\mathbf{F} \mathbf{1}_{\mathrm{ct}}$ and $\mathbf{F} \mathbf{2}_{\mathrm{ct}}$ as defined by:

$$
\mathrm{Fa}_{\mathrm{ct}}=\frac{\sum_{\mathrm{i}=1}^{N_{\mathrm{ct}}} \mathrm{fa}_{\mathrm{cti}}}{\mathrm{N}_{\mathrm{ct}}}
$$

where $\mathbf{a}=1,2$ identifies the two factors, and $\mathbf{N}_{\mathbf{c} \mathbf{t}}$ is the total number of responses in country $\mathbf{c}$ to the $\mathbf{t}$-th wave of the survey. 
The evolution over time and for each country of $\mathbf{F} \mathbf{1}_{\mathbf{c}} \mathbf{t}$ and $\mathbf{F} \mathbf{2}_{\mathbf{c}} \mathbf{t}$ (and of the respective standard deviations) is plotted in Figure 4.

Figure 4 here

In order to ascertain whether there is a systematic drift over time in the two factors, we also computed the country means of $\mathbf{f} \mathbf{1}_{\mathbf{c}} \mathbf{i}$ and $\mathbf{f} \mathbf{2}_{\mathbf{c} t} \mathbf{i}$ for the two periods, before and after 1997 , and tested whether the change occurring between the two periods is significantly different from zero. The relevant data and test statistics (allowing for different variances, since the means in each subperiod are computed over different numbers of individuals) are reported in Table 6, and the change is also plotted in Figure 5 . (Note that overall we now have only 81,649 usable observations, as non responses reduce the available sample by about $20 \%$ ).

\section{Table 6 \& Figure 5 here}

From Table 6 we note that, for all countries taken together, the means of both $\mathbf{f 1}$ and of $\mathbf{f 2}$ significantly increase from the first to the second period. More in detail, the change in $\mathbf{f 1}$ is positive in 9 out of 14 countries, which suggests that in most countries a more favorable assessment of the present and future situation is given in the second period. However, this is even more so for the mean of $\mathbf{f 2}$, where we observe only one negative change (in Belarus), which suggests an overall tendency in most other countries to re-assess more positively the communist experience as time moves forward. Figure 5 clearly shows that in a relative majority of countries (7 out of 14) there is on average a positive revision over time of both responses concerning the past (the backward factor) and the present and future (the forward factor).

For the empirical analysis to follow, however, we prefer to use the country medians, rather than the means, as this is more in accord with politico-economic theories about the relevance of median preferences. Accordingly we define $\mathbf{F M} \mathbf{1}_{\mathbf{c t}}$ and $\mathbf{F} \mathbf{M} \mathbf{2}_{\mathbf{c t}}$ as the country medians of the micro factors $\mathbf{f} \mathbf{1}_{\mathbf{c}}$ $\mathrm{t} \mathbf{l}$ and $\mathbf{f} \mathbf{2}_{\mathrm{ct} \mathrm{i}}$. Notice however that we have performed all the estimations and tests reported below also using the country means of each factor as the dependent variables, and all results are virtually identical.

\section{A framework for the analysis}

The purpose of our empirical analysis is to document the causal links that run from macro variables, institutions and reforms towards the macro factors which synthesize the median opinion about the transition process, which is prevailing in each country-year. How may we link together the stylized facts relevant to our story? Here we propose a simple framework to motivate our empirical analysis.

The process of reform. Consider a country which is pursuing a post-communist transformation, to become a democracy and a market economy. The transformation requires adopting a series of 
reforms, to favor economic restructuring and the growth of output. There are two essential, related sources of uncertainty: one is about which reforms are going to be adopted; the other is about the outcomes of reforms, once they have been adopted. In general, we may think about the reform process in the following way:

i. Citizens vote for or against a reform (which is by itself a tremendous simplification, as in general these choices are mediated by the mechanisms of indirect, representative democracy).

ii. If a majority votes for reforms, it is adopted and implemented (another tremendous simplification, as governments are almost never elected on the basis of a single-point mandate, and they often end up doing things a bit differently from their electoral programs).

iii. An adopted reform may succeed or fail to work as expected. There are two grounds for this:

- Internal reasons for success. Is the design of the reform correct? Did reformers take into account or correctly anticipate the consequences of the incentive effects induced by their reform? Did they take into account all the necessary mechanisms required to make a reform work? For instance, has the relevant information been correctly dispersed? Are the needed "reform watchers" (policemen, tax officers, lawyers, etc.) up to their tasks?

- External reasons. Nature may be of help or unhelpful. Nature refers to other variables in the scenario, which the reformers cannot act directly upon or cannot foresee. For instance there can be a financial crisis or a negative technology shock or an earthquake.

It may be argued that to some extent a better (or more cautious) and costlier design of the reform package may reduce failures due to natural causes, in practice however we can still attribute some failures to bad design and others to bad luck. In any case, although this distinction may be quite relevant in practice, we will pursue it only in a very limited way in the empirical analysis, as we cannot enter into the details of reform design.

Two other caveats need to be mentioned at the outset. First, as argued above, as a reform may involve many decisions of a potentially complementary nature, reforms may become quite complex. Hence when we name a single "reform" (e.g. privatization) in fact we may refer to the whole "reform package" that goes (or should ideally go) along with it (e.g. to include a reform of laws governing corporate finance and financial markets and intermediaries, and possibly also an insurance system for displaced workers, as well as rules related to capital and income flows across borders, and so on).

Second, we shall not focus on the processes of voting (neither citizens' vote to nominate their parliamentary representatives or the prime minister; nor the elected politicians' vote to adopt or reject reforms). Instead we shall simply focus on how the public opinion (the median citizen) will react to the adopted reforms under specific macro and institutional circumstances. Thus we also neglect all issues related to the choice or competition between alternative reform proposals or platforms. 
Characterization of reforms and of their effects. A reform is a re-organization of existing institutions. It is not necessarily costly (in budgetary terms) but it may involve some direct costs (for instance, if it requires the construction of infrastructures or to hire new personnel in charge of implementing the reform) or also indirect costs (for instance in the case that a costly complementary reform is also enacted, possibly in order to provide insurance or subsidies to workers displaced by the main reform).

Such costs need to be financed, and will reduce (due to increased taxation) the net gains accruing to those who benefit from the reform. Before we discuss how this happens, we need to characterize incomes before and after the reform.

We assume that post-communist, pro-market reforms often increase the dispersion of incomes, hence worsen the income distribution. This is because in case of a successful reform the income of the "winners" increases more, relatively to that of the "losers". We may thus evaluate each individual position after a reform package has been implemented, on the basis of the following representation:

$$
Y_{\jmath}=Y^{\circ}{ }_{j}+G^{*}+\left(G_{\jmath}+S_{\jmath}-T_{\jmath}\right)
$$

where:

$\mathrm{Y}^{\circ}{ }_{J} ; \mathrm{Y}_{J}=$ pre-; post-reform income of individual (or household) $\mathrm{J}$;

$\mathrm{G}^{*}=$ per capita average gain form the reform ( $>0$ if the reform has been successful, $<0$ otherwise);

$\mathrm{G}_{\jmath}+\mathrm{S}_{\mathrm{\jmath}}-\mathrm{T}_{\mathrm{J}}=$ additional individual net benefit from the reform, taking into account the individual specific gain $\mathrm{G}_{\mathrm{J}}$ ( $>0$ if $\mathrm{J}$ is winner; $\leq 0$ if loser) and the "redistribution package" (i.e. balance between the individual subsidy received, $\mathrm{S}_{\mathrm{J}}$, versus tax paid, $\mathrm{T}_{\mathrm{J}}$ ), if it is included in the reform. ${ }^{14}$

Ex ante, if required to express an opinion, citizens will vote in favor of a proposed reform package if they expect that their net income will increase as a consequence, that is if $E\left(Y_{J}\right)>Y_{j}^{\circ}$. This will depend, for each person, on an assessment of the joint distribution of the mean and the individual specific gains, and on the net effect of the expected compensatory measures. However, we are more concerned here with how that same citizen will react, after a reform has been implemented: again, this will depend on: (i) whether the reform has been successful on average, (ii) whether the specific position of that citizen with respect to the reform turns out to be that of a winner or a loser; (iii) whether the redistribution package enacted with the reform has provided net benefits for losers. The importance of (iii) must be stressed, in view of the assumption that reforms generally worsen the income distribution, even when they are successful. Thus, also in the case of a successful reform it will often be necessary to provide sufficient compensations to losers, in order to make reforms ex post agreeable to a majority of the population, and in particular to prevent a reform reversal.

14 If $G_{\jmath}>0$, then we might expect $S_{\jmath}-T_{\jmath}<0$, to the extent that some redistribution takes place between winners and losers. 
Empirical implications. Summing up, the framework presented so far suggests that the adoption of transitional reforms should be followed by an increase in the dispersion of incomes, and possibly also by a contemporaneous increase of average income levels (depending on the greater or lesser success of the reform). Also, a reform package may or may not include some measures of ex post redistribution between winners and losers, depending on the extent to which policy makers' choices are motivated by a desire to avoid the worsening of income distribution.

Depending on these factors (the success or failure of the reform, the design of the reform package, and thus the existence and size of possible redistribution effects) a majority of the people will express either an increase, or a decrease in their overall satisfaction with the reform process. This would then show up as an increase in the macro factor $\mathbf{F M} \mathbf{1}_{\mathbf{c t}}$, which synthesizes the median opinion prevailing in each country-year towards the present and future of the transition process. Similarly, a dissatisfaction with the outcomes of the process might also show up as an increase in the macro factor $\mathbf{F M} \mathbf{2}_{\text {ct }}$, which synthesizes the median opinion prevailing in each country-year towards the past (communist) economic and political system.

In accord with this framework, we have selected as potential explanatory variables a set of macro and institutional indicators, which describe both the extent and characteristics of the reforms adopted during the post-communist transformation and the state of the macro economy. These variables are meant to measure the extent of the reform process, the possible complementarity (or lack of) between the reforms adopted, and the macroeconomic context and consequences of those reforms.

\section{The macro drivers of the macro factors}

In this section we report the results of our search for the main determinants (drivers) of the two "macro" factors, measured by the country-year medians $\mathbf{F M} \mathbf{1}_{\mathbf{c t}}$ and $\mathbf{F M} \mathbf{2}_{\mathbf{c t}}$. In the previews section we suggested that reforms are identified by their "extent", which we can generically measure with the share of output provided by the private sector, and on the "packaging" of each reform (which is defined as the set of ancillary or accompanying reforms, which are meant either to facilitate the smooth working of the main reform, or to insure or compensate the "losers"). We also argued that the success or failure of a reform may depend on several factors, among which is the possibility of adverse macro events, which may be due to the reforms themselves or be entirely exogenous. Hence, in the same spirit of that section, we select here the following potential determinants for the two macro factors which we have identified:

- the first and the second moment of the set of nine EBRD transition indicators $\left(\mathrm{TI}^{\mathrm{m}}{ }_{\mathrm{ct}} \mathrm{t}\right.$ and $\mathrm{TI}_{\mathrm{c} t}^{\mathrm{v}}$ respectively) ${ }^{15}$;

\footnotetext{
15 The second moment is introduced to measure the dispersion of reforms: if reforms are pursued according to a homogenous pattern, taking their complementarities in full account, than the variance of reform indicators should be
} 
- a vector $\mathrm{MAC}_{\mathrm{ct}}$, which in turn includes the following four macroeconomic variables: $\mathbf{g}_{\mathrm{ct}}$ (growth rate of $G D P$ ), infl $\mathbf{c}_{\mathbf{t}}$ (annual inflation rate), $\mathbf{U}_{\mathbf{c t}}$ (unemployment rate), $\mathbf{G i}_{\mathbf{c} t}$ (Gini index of inequality of the earnings distribution);

- $\quad \mathbf{P S}_{\mathbf{c t}}$ (share of the private sector in GDP) ;

The general empirical functional form is assumed to be a distributed-lags panel model with two-way (country $\mu_{c}$ and time $\tau_{t}$ ) fixed effects. Given that we have extracted individual factor scores at the country level, it is appropriate to use the fixed effects (within) estimator, as it ignores the variation between countries, with which we cannot deal in the context of this section. In addition, Verbeek and Nijman (1992) show the consistency of the within estimator in pseudo panels like ours, where the number of individuals per cohort (cell) is very large (see the counts in Table 2).

We also assume that the determinants identified above may also interact in a number of ways, as exemplified in equation (4) below:

$$
\begin{array}{rlr}
\mathrm{FMa}_{\mathrm{ct}} & =\mu_{\mathrm{ac}}+\tau_{\mathrm{at}}+\alpha_{\mathrm{a}}(\mathrm{L})\left[\mathrm{TI}_{\mathrm{act}}^{\mathrm{m}}\left(1+\beta_{\mathrm{am}} \mathrm{MAC}_{\mathrm{ct}}\right)\right] & \\
& +\gamma_{\mathrm{a}}(\mathrm{L})\left[\mathrm{TI}_{\mathrm{act}}^{\mathrm{v}}\left(1+\beta_{\mathrm{av}} \mathrm{MAC}_{\mathrm{ct}}\right)\right] & \text { for } \mathrm{a}=1,2 \\
& +\varphi_{\mathrm{a}}(\mathrm{L})\left[\mathrm{M}_{\mathrm{act}}^{\mathrm{d}}\left(1+\beta_{\mathrm{ap}} \mathrm{PS}_{\mathrm{ct}}\right)\right]+\phi_{\mathrm{a}}(\mathrm{L}) \mathrm{PS}_{\mathrm{ct}}+\varepsilon_{\mathrm{act}} &
\end{array}
$$

where:

$\mathrm{FMa}_{\mathbf{c} t}, \mathrm{a}=1,2$ is defined as the median of the micro factor $\mathbf{f a}_{\text {ict }}$ within each country-year cluster; $\alpha(L), \gamma(L), \varphi(L)$ and $\phi(L)$ are polynomials in the lag operator up to the second order; the $\beta$ parameters measure the interaction effects; and we have introduced possible interactions between the Transition Indicators $\left(\mathrm{TI}^{\mathrm{m}}{ }_{\mathrm{ct}}\right.$ and $\mathrm{TI}_{\mathrm{ct}}^{\mathrm{v}}$ ) and the macroeconomic variables $\left(\mathrm{MAC}_{\mathrm{ct}}\right)$, and between the latter and the share of the private sector, $\mathbf{P S}_{\mathbf{c t}}$. Notice that the parameters of equation (3) are specific to each of the two factors.

The random shocks $\boldsymbol{\varepsilon}_{\text {act }}$ with a $=1,2$ are assumed to be independently distributed over time, but possibly heteroskedastic; for this, we adjust the fixed-affects standard error panel estimates to account for general heteroskedasticity, see White (1980).

Note that equation (4) reports a general model, allowing for all linear interactions between the macroeconomic and the transition variables. ${ }^{16}$ In this setup we can easily test the validity of more restricted specifications. For instance, if we were to assume that $\beta_{\mathrm{am}}=\beta_{\mathrm{av}}=\beta_{\mathrm{ap}}=0$, this implies setting all the interaction terms equal to zero.

minimal. See Staher (2005) for a wider discussion of the concept of complementarity and Braga De Macedo and Oliveira Martins (2008), who use the standard deviation of reform indicators with the same purpose as here. Also notice that the results reported in the text are robust to the use of the Herfindhal concentration index of the nine EBRD indicators instead of their standard deviations $\mathrm{TI}^{\mathbf{v}}{ }_{\mathrm{ct}}$. See the Data Appendix for more information on the data.

16 The limited number of observations prevents the inclusion of the square terms that would be included if the equation were to be interpreted as a 2 nd order approximation. 
In Tables 7 and 8 we report the sequence of general-to-specific models that have been estimated from the general framework of equation (4), respectively for the first (F1) and second (F2) factors. In each case the dependent variable is defined as the median response within each country-year cluster. $^{17}$

\section{Tables 7 and 8 here}

The first two columns in both Tables report the corresponding data congruent reductions of the general model, respectively without (column 1) and with (column 2) the inclusion of interaction terms: the $\mathrm{F}$ statistics reported in the bottom lines never reject the corresponding restrictions. Estimation results suggest that the interaction terms in column (2) make the time dummy of column (1) redundant. While parameters in column (2) of both tables are still imprecisely estimated because of multicollinearity, this specification is preferable to that of column (1), as it may be improved by economically meaningful restrictions. The final models for F1 and F2 are reported in column (3) of Tables 7 and 8 respectively. The chosen specification for $\mathbf{F} 1$ has been reduced to only four explanatory variables (three of which interacted terms) in addition to the 14 country effects; that for $\mathbf{F 2}$ contains only three interacted terms in addition to the country effects. The two final models which have emerged from the reduction of equations (4) are summarized in the following equations: ${ }^{18}$

$$
\begin{aligned}
& \mathbf{F M 1} 1_{c t}=\mu_{1 \mathrm{c}}+\alpha_{1}\left[\left(\mathrm{TI}_{\mathrm{ct}}^{\mathrm{m}}+1\right) \times \mathrm{g}_{\mathrm{ct}}\right]+\alpha_{2}\left[\mathrm{TI}_{\mathrm{ct}}^{\mathrm{m}} \times \mathrm{U}_{\mathrm{ct}}\right]+\alpha_{3}\left[\mathrm{TI}_{\mathrm{ct}}^{\mathrm{v}} \times \mathrm{g}_{\mathrm{ct}}\right]+\varepsilon_{1 \mathrm{ct}} \\
& \mathbf{F M 2} \mathbf{c}_{\mathrm{ct}}=\mu_{2 \mathrm{c}}+\beta_{1}\left[\mathrm{Gini}_{\mathrm{c}, \mathrm{t}-2} \times \mathrm{PS}{ }_{\mathrm{ct}}\right]+\beta_{2}\left[\operatorname{Infl}_{\mathrm{c}, \mathrm{t}-2} \times \mathrm{PS}_{\mathrm{ct}}\right]+\varepsilon_{2 \mathrm{ct}}
\end{aligned}
$$

We immediately notice that the explanatory variables for the two factors are completely different. This is essentially coherent with F1 and F2 being orthogonal by construction. We acknowledge that in practice these two factors have been identified only on the basis of a statistical decomposition, hence our results should not be interpreted as suggesting any kind of schizophrenic decision process; they may instead be interpreted as suggesting the usefulness of our method of classifying the independent variables on the basis of whether they are used for making assessments of the present and future or of the past. We also notice that interaction effects are largely dominant in both equations, and they are "correctly" signed according to our expectations:

- For FM1 (the forward factor) the "median opinion" expressed by the individuals interviewed in each country and time is influenced by the interaction between the state of reforms (average and variance of the reform indicator) and the state of the macro economy ( $g$ and $U$ ).

\footnotetext{
${ }^{17}$ Estimates with average values are very similar to those with median values.

${ }^{18}$ These equations also contain a change in notation, as the $\alpha$ now refer to the coefficients in the equation for FM1, and the $\beta$ to that for FM2. A note of caution is required when looking at these results, as the limited number of observations in the time dimension (only about six waves of interviews per country on average) may have weakened the efficiency of the testing procedure.
} 
- Progress in transitional reforms (measured by an increase in the average level of the transition indicators ) affects positively the median opinion about the present and the future. A positive growth rate adds to this positive effect ( $\alpha_{1}$ positive), while an increase in unemployment detracts from it ( $\alpha_{2}$ negative). ${ }^{19}$

- We notice a marked negative effect of not exploiting the complementarity of reforms, which is also reinforced by a stronger GDP growth ( $\alpha_{3}$ negative): this possibly suggests that faster growth increases the perceived urgency of a well-balanced reform package.

- For FM2 (the backward factor) results are driven by three macroeconomic variables which mostly affect negatively the welfare of the losers (and thus increase their "nostalgia" for the past): the rate of inflation, the worsening distribution of earnings and an increasing share of the private sector.

- The first two variables enter through an interaction with the third one (the share of the private sector in GDP). Our interpretation is that privatization is perceived to have negative effects (and to increase "nostalgia" for the past) insofar as it is observed together with a worsening of inflation or of the distribution of incomes. ${ }^{20}$

- No measure of transition reforms seems to affect the evaluation of the past.

To validate the robustness of these results, we conduct two different tests of specification. The first test follows from the procedure adopted by Rovelli and Zaiceva (2011), who argue that "statements about the past and the present are not independent of each other, but rather reinforce each other". To take this into account they compute the dependent variables by taking the difference (or "distance") between evaluations about the present and the past. In the same spirit, we compute a new dependent variable, defined as the difference between the forward and the backward factors, FM1 and FM2 respectively. We model this variable following the same specification strategy reported in Tables 7 and 8. Perhaps unsurprisingly, the results of the new specification search are coherent with those reported in those tables: we end up with a set of explanatory variables equal to the union of the two sets of variables included in column (3) of Table 7 and 8; also the new estimated coefficients are almost identical (within one standard deviation) to the original ones (apart from the obvious change of sign for the explanatory variables of FM2). ${ }^{21}$

\footnotetext{
${ }^{19}$ In these regressions we have only used $\mathrm{TI}^{\mathrm{m}}$ (average) and $\mathrm{TI}^{\mathrm{v}}$ (standard deviation) of the nine transition indicators. In principle it would be interesting to explore the role of each single indicator, but this is discouraged by the high correlation between them. In the correlation matrix of all the TI measures relevant to our sample, the minimum bivariate correlation is 0.64 (between indicators of price and financial market liberalization), while all the other values are above 0.7 , and some as high as 0.92 (between bank and infrastructure reforms). Hence we do not pursue this analysis.

${ }^{20}$ Note that in the equation for FM2 both Gini and Inflation enter with a 2-year lag. Lags are defined as the number of solar years before the relevant survey year.

${ }^{21}$ We do not report these results to save space, they are available if requested.
} 
A second test of our specification looks how appropriate it is to assume that countries differ only by their specific fixed effects. In Table 10 we thus report the results of the tests for predictive failure, conducted by re-estimating the chosen models for FM1 and FM2, excluding from each one country at a time. Out of 28 tests, we observe a predictive failure at $10 \%$ only in 5 cases, and never at $1 \%$. The result of these tests thus strongly supports the poolability of the different countries into a single model. This validates the modeling choice which we have adopted so far (based on the idea that the same macro-institutional variables could explain changes in people's judgments across time for all countries). However, this result also suggests another way of exploiting or rather building on this result, which we pursue in the next session.

Table 9 here

\section{The institutional drivers of the country effects}

In the previous section, we explored the determinants of the median opinion, within each country and across time. To this purpose, we measured each pair of factors independently for each country. This implies that, on the average of all individual responses for each country, each factor averages to zero. $^{22}$ As we have validated the poolability of our model across countries (see Table 9 and comments in the previous section), we are now tempted to "pool" also the extraction of the two factors. We anticipate that this more restrictive procedure will be validated below, and this result will allow us to conduct a meaningful analysis of the differences between the country fixed effects.

As a first step, we re-compute the principal components for the six basic response variables for the overall sample (all countries and all years), that is across 81,649 individual observations. Almost identically to the previous analysis, the first two components explain $72 \%$ of the overall variance. Of the two, the first component (which we now call $\mathbf{w} \mathbf{1}_{\mathbf{i} \mathbf{c}}$ ) is again related mainly to four of the response variables, those focused on the present or future (PRESEC and PRESPOL; FUTEC and FUTPOL), and the second component $\left(\mathbf{w} \mathbf{2}_{\mathbf{i} \mathbf{~}}\right.$ ) is related to the other two responses, focused on the past (PASTEC and PASTPOL). The $R^{2}$ of the regressions of the responses on the factors are all above 0.77 for $\mathbf{w} \mathbf{1}_{\mathbf{i} \mathbf{c}} \mathbf{t}$ and around 0.90 for $\mathbf{w} \mathbf{2}_{\text {ic t }}{ }^{23}$

As a second step, we compute the median values of the micro factors $\mathbf{w} \mathbf{1}_{\mathbf{i} \mathbf{c}}$ and $\mathbf{w} \mathbf{2}_{\mathbf{i} \mathbf{c}} \mathbf{t}$ within each country-year cluster; these are defined respectively as $\mathbf{W} \mathbf{M} \mathbf{1}_{\mathbf{c}} \mathbf{t}$ and $\mathbf{W} \mathbf{M} \mathbf{2}_{\mathbf{c}}$ t. These are the new dependent variables, for a "macro" regression model, analogous to that reported in Tables 7 and 8 above. We perform the same procedure of general to specific reductions, which leads to a new set of

\footnotetext{
${ }^{22}$ Although strictly speaking the medians are not constrained to become zero in each country-year cluster, it is clear that this procedures also obscures a source of differences between the country-year medians.

${ }^{23}$ These numbers can be compared with those reported in section 3.1 and in Figure 3.
} 
estimates, almost identical to those reported in columns (3) of Tables 7 and 8 . We report the final results of this procedure, in Tables 10 and 11 respectively. In all cases, the results are striking: independently of whether we have computed each factor on a country base (as for $\mathbf{f 1}, \mathbf{f 2}$ ) or over the whole sample (as for w1, w2) the difference between the two sets of computations is reflected almost only in the estimates of the fixed effects, whereas the selection of the other regressors and the values and significance of all individual coefficients are very similar. To ease this comparison, in column (1) of Tables 10 and 11 we reproduce the final estimates from column (3) of Tables 7 and 8 respectively, adding however the individual fixed effects, which we had not shown before. In column (2) of Tables 10 and 11 we show the same regression as in column (1), but using the dependent variable computed over the whole sample: in each case the difference between estimates in columns (1) and (2) is clearly limited to the estimates of the fixed effects. ${ }^{24,}{ }^{25}$ This is remarkable, as it suggests that country fixed effects can be explained on the basis of variables, which are different from those already included in Tables 7 and 8 and which apparently capture the variability of the dependent variable only in the time dimension.

Tables 10 and 11 here

How than could we capture variability in the spatial dimension? To this purpose, we search for different explanatory variables; we focus in particular on measures of cross-country institutional differences. ${ }^{26}$ In Figures 6, 7 and 8 we plot the visual correlations of four such variables with the estimated country fixed effects (from columns (2) of Tables 10 and 11 respectively). In particular we observe:

(i) a strong positive correlation between the estimated country fixed effect from the equation for WM1 (the "forward" factor) and the indicators of Rule of Law and Control of Corruption ${ }^{27}$;

(ii) and (ii) a strong positive (negative) correlation between the estimated country fixed effect from the equation for WM2 (the "backward" factor) and the Mortality Rate (Life Expectancy) indicators. $^{28}$

\footnotetext{
${ }^{24}$ Note that the adjusted R-squares are not comparable between columns (1) and (2), because of the difference in their method of computation.

25 As we explained previously, the country-averages of the factors computed at the country level are all zero by construction.

${ }^{26}$ We considered in particular six World Bank Governance Indicators: Voice and Accountability, Political Stability, Government Effectiveness, Regulatory Quality, Rule of Law, Control of Corruption. In addition we included also Adult Mortality and Life Expectancy from the WDI. See the Data Appendix. For each indicator we used the country average for the available time periods.

${ }^{27}$ The sample correlation between the estimated country fixed effects from the model in Table 10 and the Rule of Law and Control of Corruption indicators is respectively: $0.81 ; 0.79$. The correlation between the two indicators is 0.98 (based on 14 country averages).
} 


\section{Insert Figures 6 and 7 here}

These patterns of correlations are quite plausible, as it is natural to expect that the opinion of the median (or average) citizen about the post-communist experience (and the adopted reforms) should be strongly influenced in each country by the four indicators reported above. More precisely, evaluations about the present and the future (embodied in factor f1, and hence in WM1) are affected by the strength and well-functioning of the institutional environment (measured by indicators of the Rule of Law or Control of Corruption) while "nostalgia" for the past (embodied in factor $\mathbf{f 2}$, and hence in WM2) is enhanced by indicators of ill-functioning of the present system (such as an increase in the rate of mortality or a decrease in life expectancy).

The next task is to insert these indicators in the relevant regressions. Results are reported in columns (3) and (4) of Tables 10 and 11. In each column, we have also deleted the fixed effects which are no longer significantly different from zero after the inclusion of the new variables. Consider for instance column (3) of Table 10. With the inclusion of Rule of Law (which has a strong significant positive effect on WM1), the goodness of fit improves (as measured by smaller RMSE), the main explanatory variables retain their values and significance, and most of the country effects disappear (that is, they become insignificantly different from that of Hungary, the country on which we had parametrised the constant term in columns (1) and (2)). In fact the only remaining country effects are those for Bulgaria, Czech Republic, Poland and Estonia, all of which are significantly positive: this implies that in these four countries the satisfaction for the post-communist experience goes beyond the positive effects of the improved Rule of Law. On the other hand it is noteworthy that the strong negative country effect for Russia reported in column (2) entirely disappears when the (lack of ) Rule of Law is introduced in the equation.

Almost identical remarks can be made for the introduction of Control of Corruption in column (4) of Table 10. In fact these two indicators (Rule of Law and Control of Corruption) are strongly correlated with each other hence their explanatory power is similar in all respects.

Two other indicators (Mortality and Life Expectancy) perform similar roles in Table 11, columns (3) and (4), although now the number of vanishing country fixed effects is smaller (about half of the countries).

\footnotetext{
${ }^{28}$ The sample correlation between the estimated country fixed effects from the model in Table 11 and the Mortality Rate and Life Expectancy indicators is respectively: $0.67 ;-0.63$. The correlation between the two indicators is -0.97 (based on 14 country averages).
} 


\section{Summing up and conclusions}

Although the experience of the post-communist transition has been broadly successful, numerous signs of "transition fatigue" and of nostalgia for the previous regime have also appeared. Our purpose in this paper has been to assess how the post-communist transformations have affected the peoples' perceptions of their economic and political systems. In particular, we have sought to identify the macro and institutional drivers of the (median) public opinion. For this purpose, we have transformed the individual data, originated with the surveys conducted by the New Democracy Barometers from 1991 to 2004, into an aggregate macro pseudo-panel, with 89 country-year clusters, based on 13 countries observed during that period.

We have used factor analysis to summarize the available data. In fact, our intermediate findings imply that the overall variability of responses across individuals, countries and time is adequately summarized by only two factors, which jointly explain between $66 \%$ and $75 \%$ of the overall variability.

We also find that, for all countries in our sample, (i) responses about the present and future are very closely related, and different from those about the past; (ii) at any point in time, responses about the polity are closely related to those about the economy.

These intermediate results have allowed us to conduct our macro analysis by focusing on only two macro (aggregate) factors, which can be intuitively interpreted as representing, respectively, the median opinion about the present and future state of the economic and political system, and the median opinion about the past. We have then modeled how these opinions have been shaped by institutional and macro variables. Our results in this respect are quite robust and amenable to a clear interpretation. A synthetic summary of the results is that:

i. When the economy is growing, on average people appreciate more extensive reforms; they dislike unbalanced reforms.

ii. Nostalgia for the previous regime is heightened by increasing inequality in the distribution of incomes and by higher inflation. In particular, the effects of both variables come through an interaction with increases in the private sector share in GDP: in a way, this suggests that people attribute to private capitalism the cause of both a worsening income distribution and higher prices.

iii. Cross-country differences in the attitudes towards the present and future are largely explained by differences in the institutional indicators for the rule of law and corruption.

iv. Cross-country differences in the extent of nostalgia towards the past are mainly related to differences in the deterioration of standards of living.

In our view, these results have also clear policy implications, as they underlay the importance of exploiting reform complementarity and of ensuring the inclusiveness of the reform outcomes. Also, 
they are a useful reminder that institutional quality and good governance are essential ingredients of successful reforms.

\section{References}

Aghion, P., and Blanchard, O.-J. (1994). On the Speed of Transition in Central Europe. NBER Macroeconomics Annual, 283-319.

Anderson, T.W. (1974). An Introduction to Multivariate Analysis, Wiley.

Boeri, T., and K. Terrell (2002). Institutional Determinants of Labor Reallocation in Transition. Journal of Economic Perspectives, 16 (1): 51-76.

Braga De Macedo, J., and Oliveira Martins, J. (2008). Growth, reform indicators and policy complementarities. Economics of Transition, 16(2): 141-164. DOI: 10.1111/j.14680351.2008.00323.x

Campos N., and F. Coricelli (2002). Growth in Transition: What We Know, What We Don't, and What We Should. Journal of Economic Literature, XL: 793-836.

Denisova, I., Eller, M., Frye, T., and Zhuravskaya, E. (2007). Who Wants to Revise Privatization and Why? Evidence from 28 Post-Communist Countries. CEPR Discussion Paper No. 6603.

Easterlin, R. A. (2009). Lost in Transition: Life Satisfaction on the Road to Capitalism. Journal of Economic Behavior \& Organization 71: 130-145.

EBRD (2007a). Life in Transition. European Bank for Reconstruction and Development, London, UK. (http://www.ebrd.com/pubs/econo/lit.htm)

EBRD (2007b). Transition Report: People in Transition. European Bank for Reconstruction and Development, London, UK.

Fernandez, R., and Rodrik, D. (1991). Resistance to Reform. Status Quo Bias in the Presence of Individual-Specific Uncertainty. American Economic Review, 81: 1146-55.

Fidrmuc, J. (2000). Political Support for Reforms: Economics of Voting in Transition Countries. European Economic Review, 44: 1491-1513.

Gächter, S., and Riedl, A. (2002). Moral Property Rights in Bargaining. CESifo Working Paper Series No. 697.

Guriev, S., and Zhuravskaya, E. (2009). (Un)Happiness in Transition. Journal of Economic Perspectives, 23(2):143-168.

Hayo, B. (2004). Public Support for Creating a Market Economy in Eastern Europe. Journal of Comparative Economics, 32: 720-44. 
Kim, B-Y. and Pirttilä, J. (2006). Political Constraints and Economic Reform: Empirical Evidence from the Post-Communist Transition in the 1990s. Journal of Comparative Economics, 34: 446-66.

Landier, A., Thesmar, D. and Thoenig, M. (2008). Investigating Capitalism Aversion. Economic Policy, July: 465-97.

Milanovic, B., and Ersado, L. (2008). Reform and Inequality during the Transition: An Analysis Using Panel Household Survey Data, 1990-2005. World Bank Policy Research Working Paper, No. 4780.

Munro, Neil M. I. (2006). Russia's Persistent Communist Legacy: Nostalgia, Reaction and Reactionary Expectations. Post-Soviet Affairs, 22 (4): 289-313.

Minsky, H.P. (1996). Uncertainty and the Institutional Structure of Capitalist Economies. Levy Economics Institute WP No.155.

Rose, R., Mishler, W., and Haerpfer, C. (1998). Democracy and its Alternatives, Polity Press.

Rovelli, R., and Zaiceva, A. (2009). Transition fatigue? Cross-country evidence from micro data. IZA Discussion Paper, No. 4224.

Rovelli, R., and Zaiceva, A. (2011). Individual support for economic and political changes: Evidence from transition countries, 1991-2004. Università di Bologna - DSE Working Paper, No. 734.

Staehr, K. (2005). Reforms and Economic Growth in Transition Economies: Complementarity, Sequencing and Speed. The European Journal of Comparative Economics, 2 (2): 177-202.

Staehr, K. (2006). Linkages between political and economic reforms in the post-communist countries", Nordic Journal of Political Economy, 32(2): 113-138.

Svejnar, J. (2002). Transition Economies: Performance and Challenges. Journal of Economic Perspectives, 16 (1): 3-28.

Verbeek, M., and Nijman T. (1992). Can Cohort Data Be Treated as Genuine Panel Data? Empirical Economics 17(1): 9-23.

White, H. (1980). A Heteroskedasticity-Consistent Covariance Matrix Estimator and a Direct Test for Heteroskedasticity. Econometrica 48(4): 817-838. 


\section{Data Appendix}

Individual (survey) data

Sources: New Europe Barometer (waves I-VII), New Russia Barometer (waves I-XIII) and New Baltic Barometer (waves I-VI). These data have been produced by the Centre for the Study of Public Policy, University of Aberdeen/University of Strathclyde, sponsored by the Austrian Federal Ministry of Science and Research, Austrian National Bank and Paul Lazarsfeld Society (Vienna), as well as by the Centre for the Study of Public Policy, Bank of Sweden, Tercentenary Foundation, Economic and Social Research Council, MacArthur Foundation (Chicago), and supplied by the UK Data Archive. The data are Crown copyright. The original data creators, depositors or copyright holders, and the UK Data Archive bear no responsibility for the present analysis or interpretation of these data.

The following data were obtained directly from the UK Data Archive:

Rose, R., New Europe Barometer I-V, 1991-1998 [computer file]. Colchester, Essex: UK Data Archive [distributor], October 2005. SN: 5241.

Rose, R., New Europe Barometer VI, 2001 [computer file]. Colchester, Essex: UK Data Archive [distributor], October 2005. SN: 5242.

Rose, R., Mishler, William, New Europe Barometer VII, 2004-2005 [computer file]. Colchester, Essex: UK Data Archive [distributor], July 2007. SN: 5243.

Rose, R., New Russia Barometer, 2000-2001 [computer file]. Colchester, Essex: UK Data Archive [distributor], November 2003. SN: 4550.

Rose, R., New Russia Barometer XIII, 2004 [computer file]. Colchester, Essex: UK Data Archive [distributor], August 2007. SN: 5700.

The data listed above have been coded into a single dataset as described by Rovelli and Zaiceva (2009).

\section{Macroeconomic variables and institutional and reform indicators}

- GDP growth rate. GDP per capita PPP (constant 2000 international USD, annual rate of growth)). Source: World Development Indicators (WDI, http://econ.worldbank.org/).

- Inflation. GDP deflator (annual rate). Source: WDI.

- Unemployment rate. Source: EBRD. (For Belarus: IMF International Financial Statistics; for Estonia in 1990 and 1991 and for Ukraine: WDI,)

- Gini index for the distribution of earnings. Source: Transmonee dataset, release 2008, http://www.transmonee.org/. Missing data have been interpolated using the Gini index for the distribution of incomes were available, or linearly otherwise.

- Private sector share in GDP. Source: EBRD online data table-Structural Change Indicators http://www.ebrd.com/country/sector/econo/stats/index.htm.

- EBRD Transition Indicators . Source: EBRD (2007b).

- World Bank Governance Indicators (http://info.worldbank.org/governance/wgi/sc chart.asp): Voice and Accountability, Political Stability, Government Effectiveness, Regulatory Quality, Rule of Law, Control of Corruption (for each indicator, average of values for 1996-2004).

- Adult Mortality Rate (Total deaths per 1000 adults). Source: WDI (average 1991-2004).

- Life Expectancy at Birth (Number of years). Source: WDI (average 1991-2004). 
Figures and Tables

Figure 1. Correlations among responses which also involve judgments about the past ${ }^{\text {a }}$
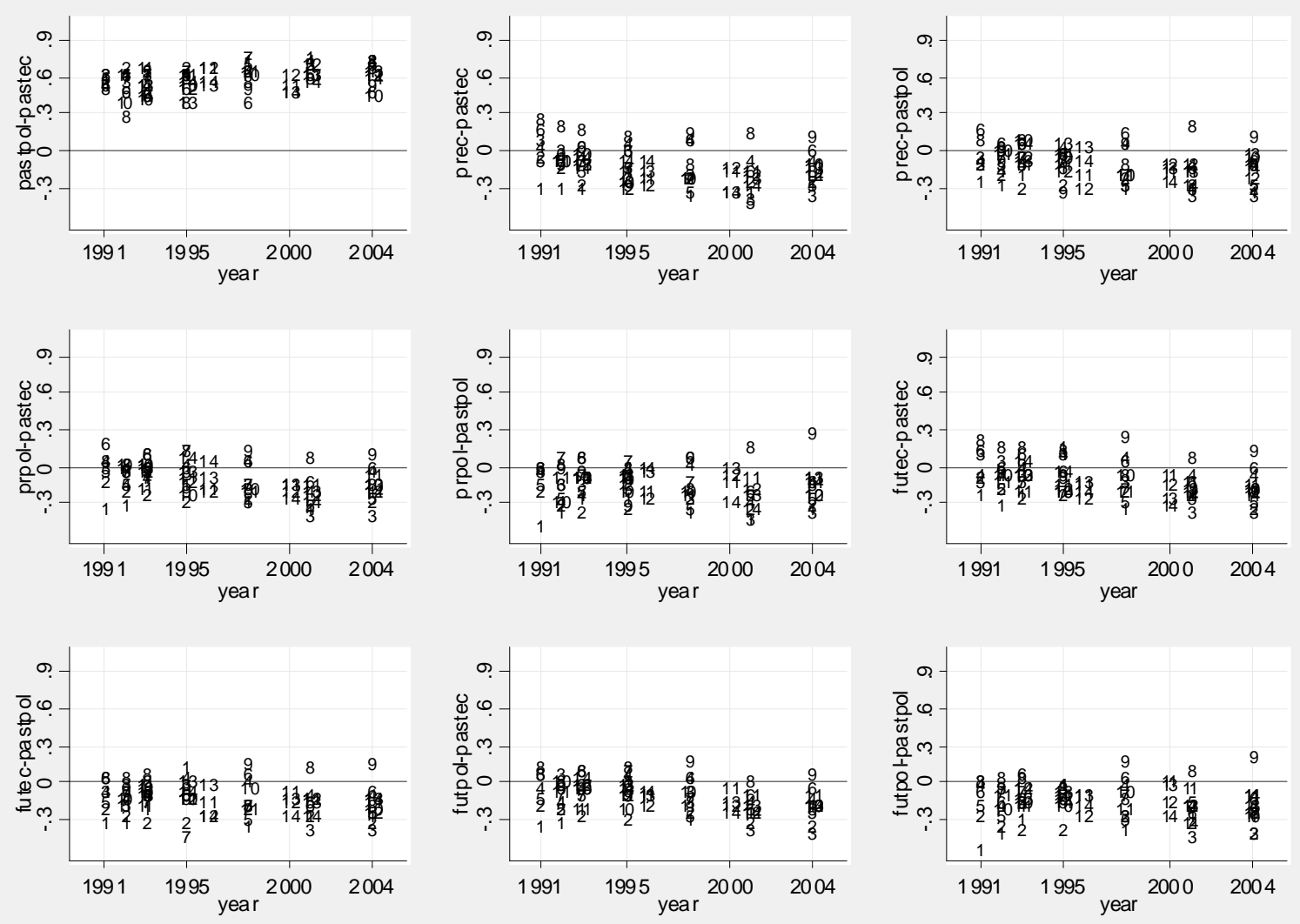

a Each country is represented by the code number, see the first column of Table2.

Figure 2. Correlations among responses which do not involve judgments about the past ${ }^{\text {a }}$
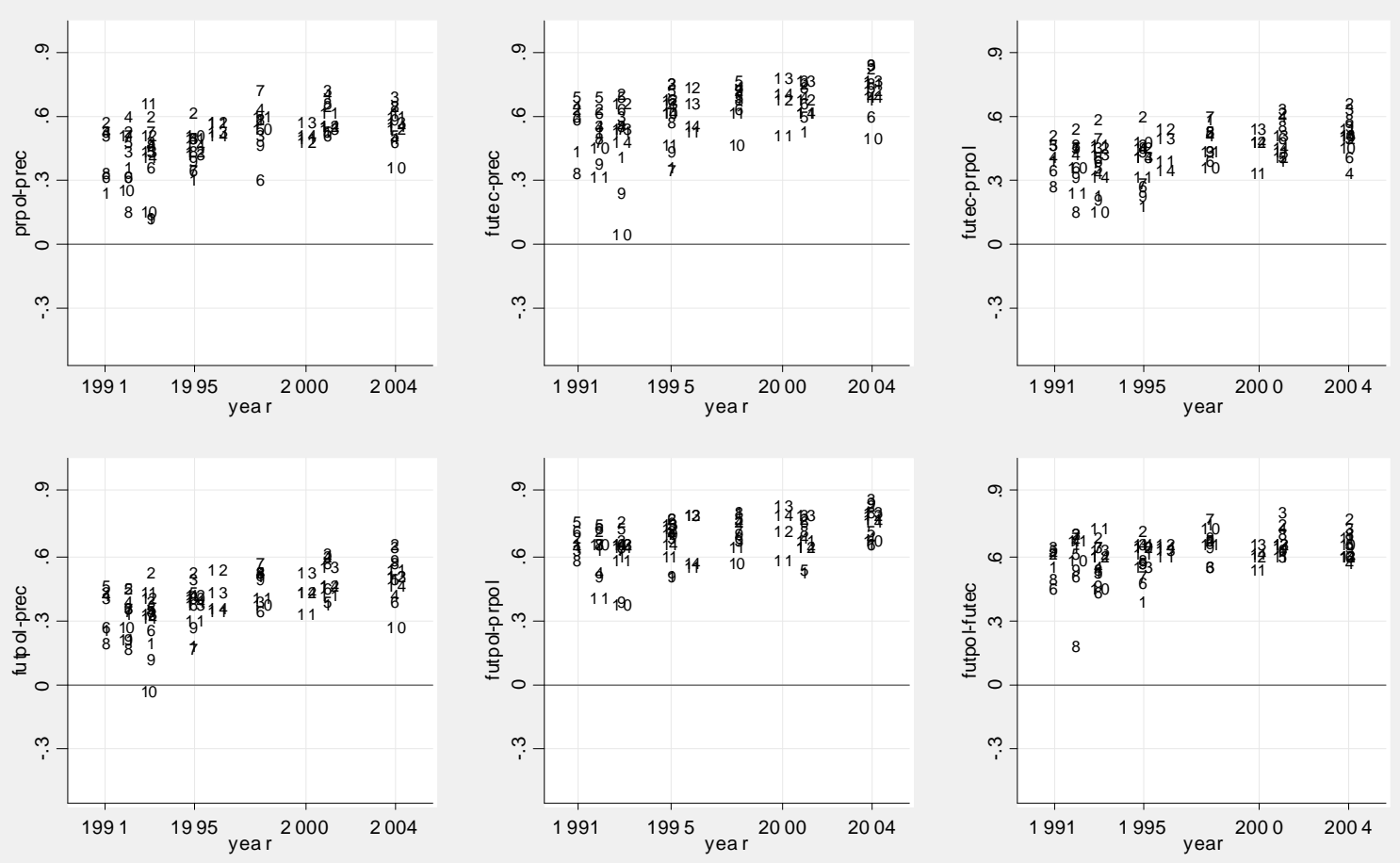

\footnotetext{
${ }^{\text {a }}$ See the footnote to Figure 1.
} 


\section{Figure 3. Explanatory power of each factor by response variable ${ }^{a, b}$}
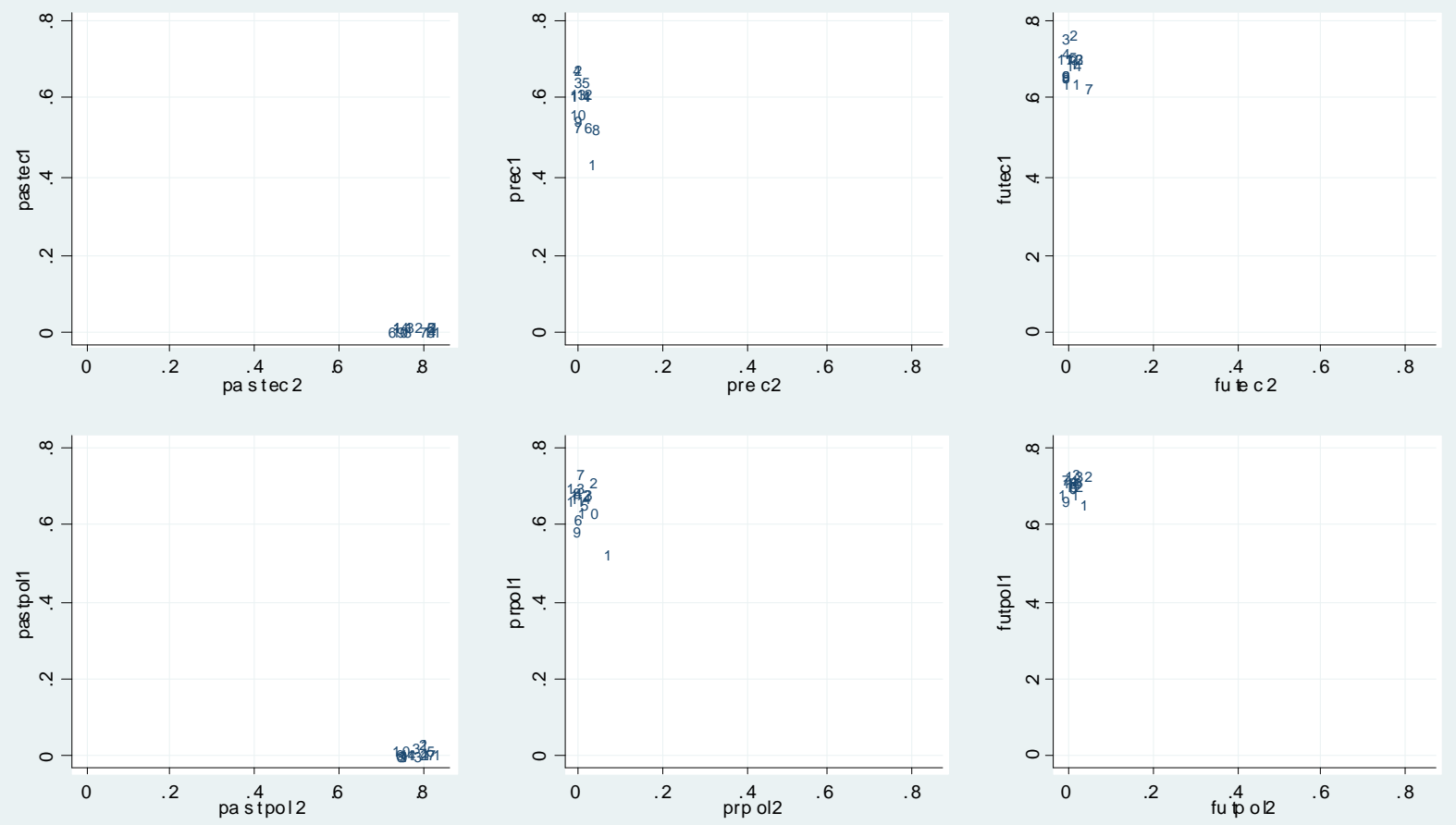

a Explanatory power is measured by the $\mathrm{R}^{2}$ from country-level regressions of each response variable against one factor at a time. Along the $y$-axes we report the $R^{2}$ of the regressions against $\mathbf{f 1}_{c, t, i}$; along the $x$-axes the $R^{2}$ of the regressions against $\mathbf{f} \mathbf{2}_{\mathbf{c}, \mathrm{t}, \mathrm{i}}$.

${ }^{b}$ The first (second) row of plots the $\mathrm{R}^{2}$ from regressions where the dependent variables are the responses relative to the economic (political) situation, the three columns refer respectively to responses about the past, present and future. Within each plot, each point refers to the $R^{2}$ for a country regression (country codes 1-14 are reported in the first column of Table 2. 
Figure 4. Time patterns of mean and standard deviation of F1 (above) and F2 (below), by country ${ }^{\mathrm{a}}$
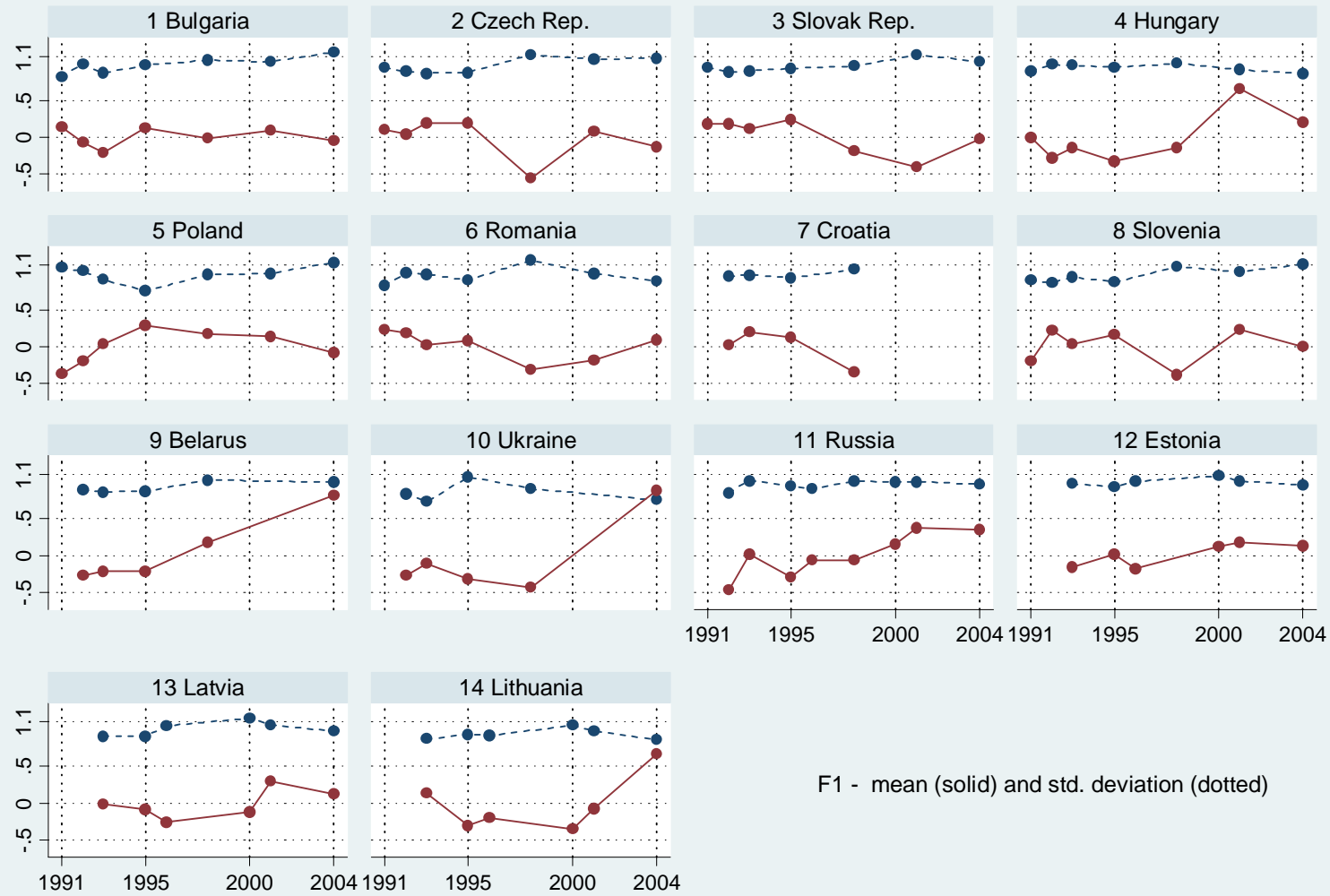

F1 - mean (solid) and std. deviation (dotted)
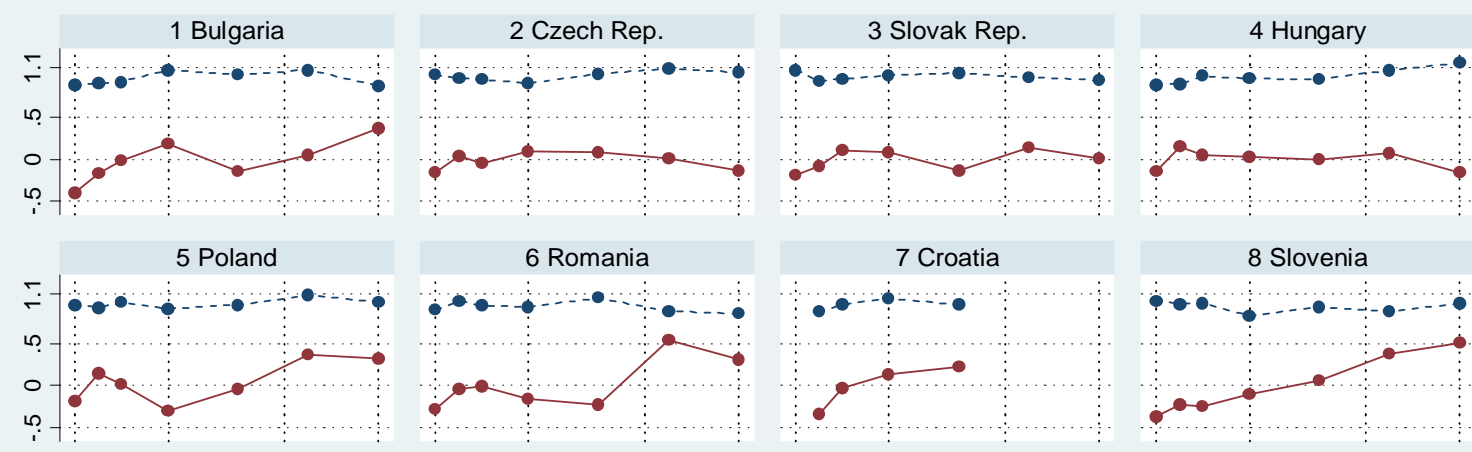

6 Romania

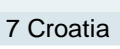

8 Slovenia
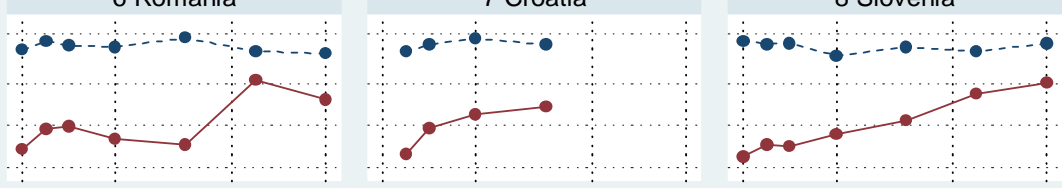

9 Belarus

10 Ukraine

11 Russia

12 Estonia
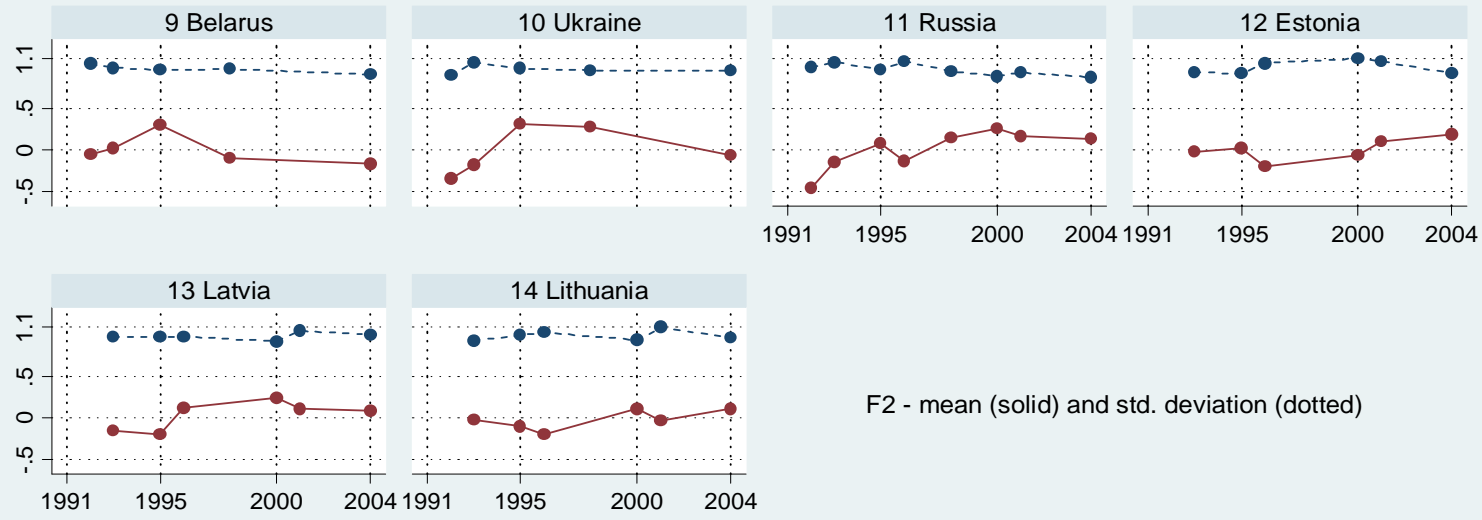

14 Lithuania

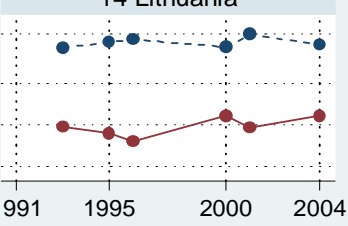

F2 - mean (solid) and std. deviation (dotted)

${ }^{a}$ Each dot corresponds to a surveyed year, data gaps are interpolated within country. Overall, there are 89 dots, corresponding to the 89 country-year clusters in Table 2. By construction each country mean and standard deviation across all periods are respectively zero and one. 
Figure 5. Average changes in the score of $\mathrm{f} 1$ and $\mathrm{f} 2$ in each country: before/after 1997

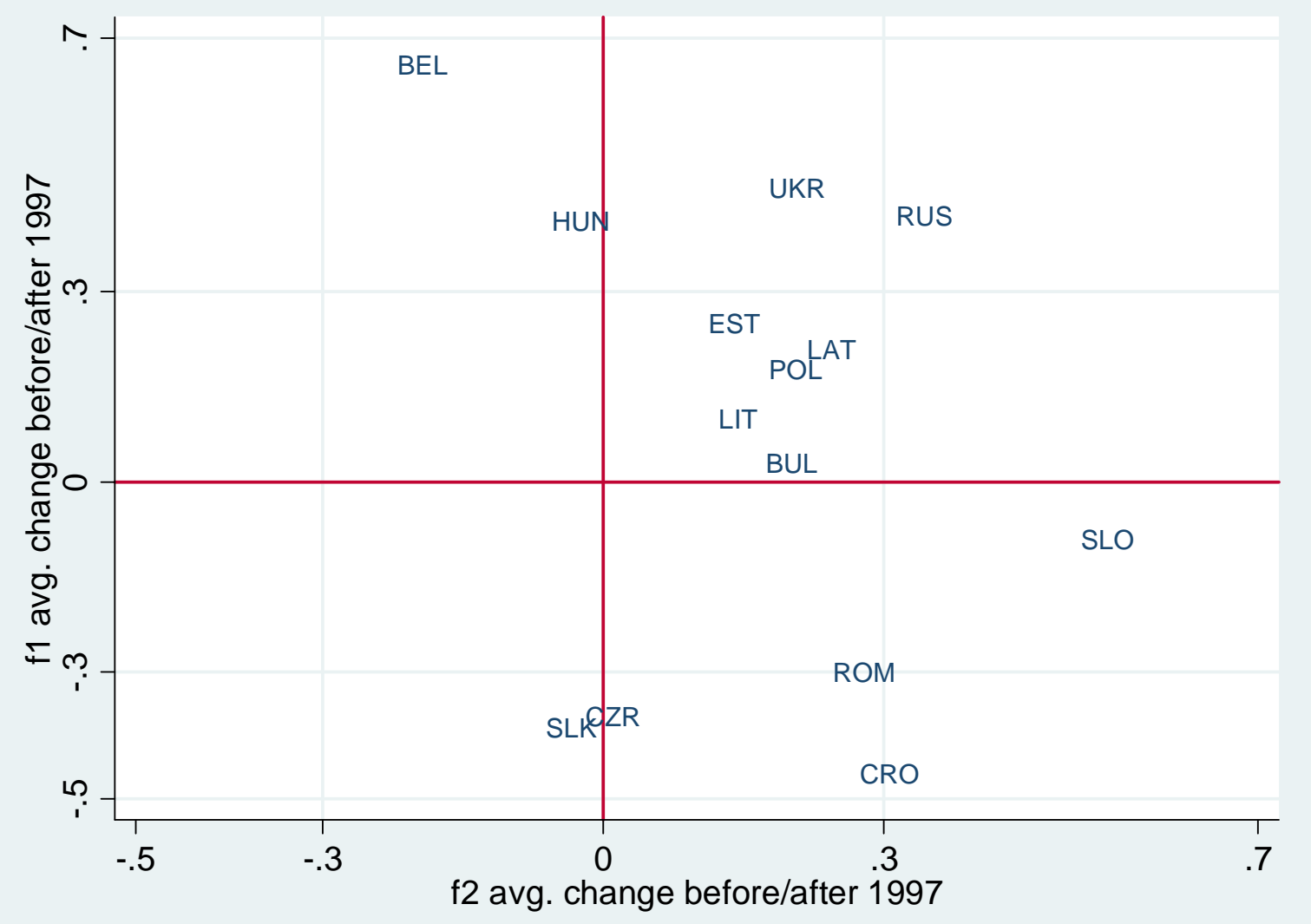


Figure 6 - Correlation between country fixed effects for WM1 and two institutional variables:

(a) Rule of Law

(b) Control of Corruption
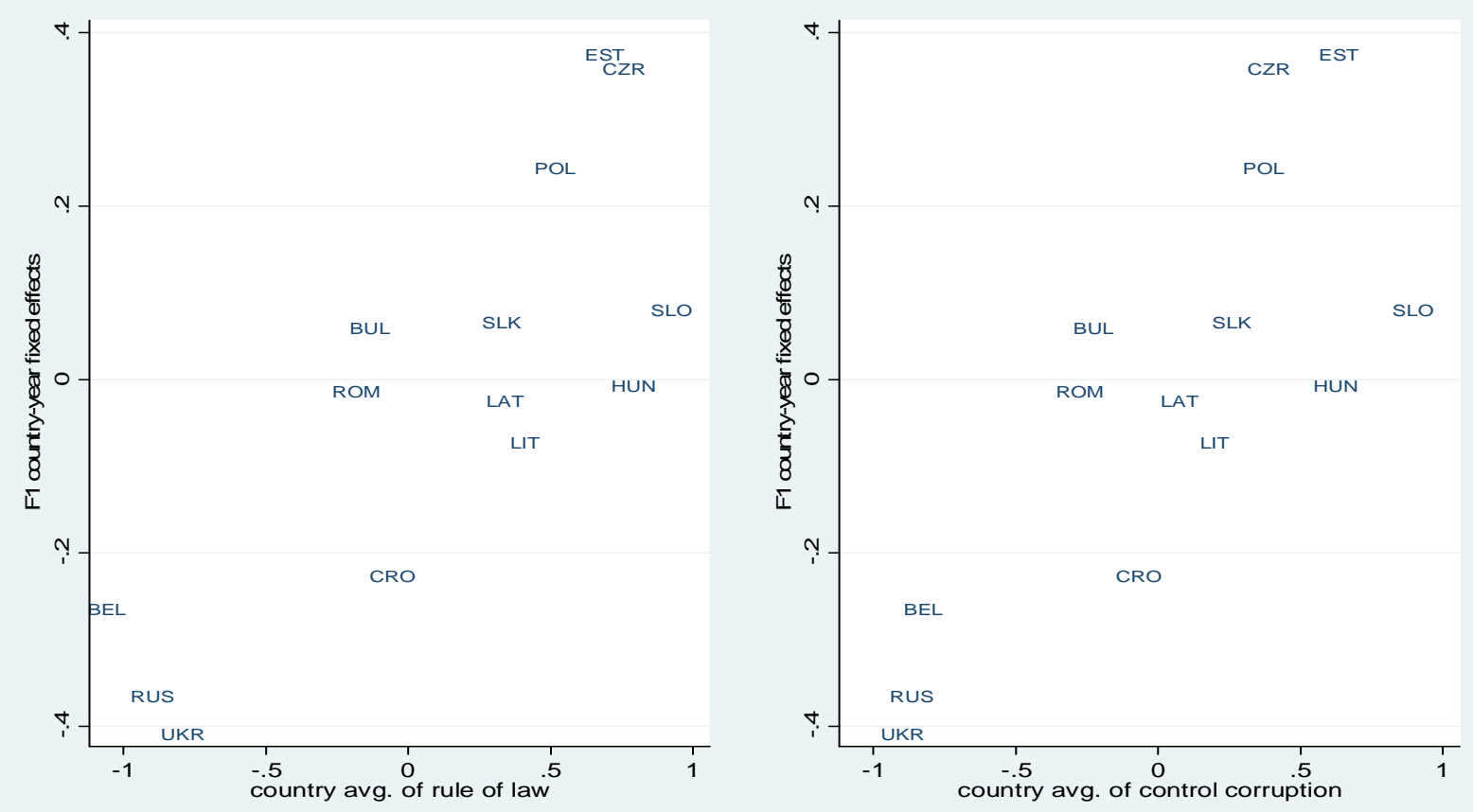

Figure 7 - Correlation between country fixed effects for WM2 and two institutional variables:

(a) Mortality Rate

(b) Life Expectancy at Birth
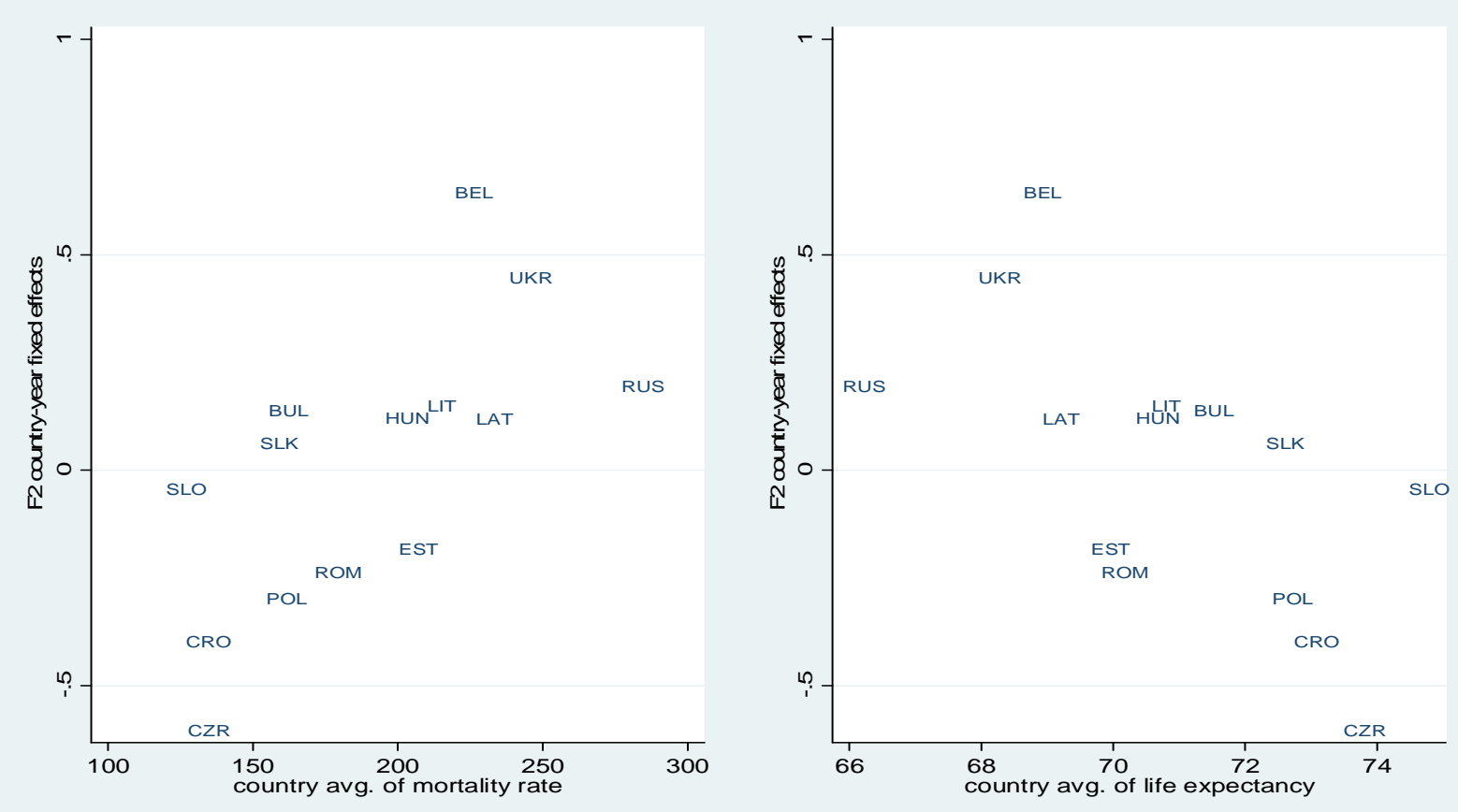
Table 1. The six basic questions and corresponding answer codes

\begin{tabular}{|c|c|c|c|}
\hline & $\begin{array}{l}\text { Here is a scale for ranking how } \\
\text { the economic system works }\end{array}$ & & $\begin{array}{l}\text { ere is a scale for ranking how } \\
r \text { system of government works }\end{array}$ \\
\hline & $\begin{array}{r}\text { The top, plus 100, is the bes } \\
\text { Where on thi }\end{array}$ & $\begin{array}{l}\text { the botto } \\
\text { scale wou }\end{array}$ & $\begin{array}{l}\text { minus } 100 \text {, the worst. } \\
\text { ou put: }\end{array}$ \\
\hline PASTEC: & $\begin{array}{l}\text { the Socialist economic system before } \\
\text { the revolution of } 1989\end{array}$ & PRESPOL: & the former Communist regime \\
\hline PRESEC: & our current economic system & PRESPOL: & $\begin{array}{l}\text { our current system of governing with free } \\
\text { elections and many parties }\end{array}$ \\
\hline FUTEC: & our economic system in five years time & FUTPOL: & $\begin{array}{l}\text { our system of governing five years in the } \\
\text { future }\end{array}$ \\
\hline
\end{tabular}

- This question is phrased differently in some countries, e.g. in Russia.

Table 2. The NEB Surveys: Sample dimension by country and time

\begin{tabular}{|lccccccccccc|}
\hline \multicolumn{1}{c}{ Year: } & 1991 & 1992 & 1993 & 1995 & 1996 & 1998 & 2000 & 2001 & 2004 & Total & \% share \\
Code. Country: & & & & & & & & & & & \\
1. Bulgaria & 1002 & 1164 & 1139 & 1181 & & 971 & 1163 & 1231 & 7851 & 7.7 \\
2. Czech R. & 660 & 1275 & 1103 & 908 & & 961 & 1101 & 967 & 6975 & 6.8 \\
3. Slovakia & 291 & 569 & 531 & 1010 & & 923 & 1002 & 1036 & 5362 & 5.2 \\
4. Hungary & 923 & 864 & 971 & 1018 & & 973 & & 1577 & 990 & 7316 & 7.1 \\
5. Poland & 1130 & 1063 & 980 & 949 & & 1141 & & 1000 & 943 & 7206 & 7.0 \\
6. Romania & 986 & 999 & 1000 & 996 & & 1192 & & 1001 & 1110 & 7284 & 7.1 \\
7. Croatia & & 1000 & 1000 & 1000 & & 1000 & & & & 4000 & 3.9 \\
8. Slovenia & 1049 & 1011 & 984 & 997 & & 974 & & 1098 & 1000 & 7113 & 6.9 \\
9. Belarus & & 1222 & 1056 & 1000 & & 1000 & & & 1000 & 5278 & 5.2 \\
10. Ukraine & & 993 & 945 & 1000 & & 1161 & & & 2000 & 6099 & 6.0 \\
11. Russia & & 2106 & 1973 & 1951 & 2374 & 1904 & 1907 & 2000 & 2068 & 16283 & 15.9 \\
12. Estonia & & & 1987 & 1296 & 971 & & 1048 & 943 & 940 & 7185 & 7.0 \\
13. Latvia & & & 2137 & 1173 & 952 & & 966 & 1001 & 956 & 7185 & 7.0 \\
14. Lithuania & & & 2012 & 870 & 1000 & & 1112 & 1124 & 1113 & 7231 & 7.1 \\
Total & 6041 & 12266 & 17818 & 15349 & 5297 & 12200 & 5033 & 13010 & 15354 & 102368 & 100.0 \\
\multicolumn{1}{c}{ \% share } & 5.9 & 12.0 & 17.4 & 15.0 & 5.2 & 11.9 & 4.9 & 12.7 & 15.0 & 100.0 & \\
\hline
\end{tabular}


Table 3. Basic statistics, whole sample

\begin{tabular}{|lcccccc|}
\hline \multicolumn{1}{l}{ Past } & \multicolumn{5}{c}{ Present } \\
\hline Variables: & PASTEC & PASTPOL & PRESEC & PRESPOL & FUTEC & FUTPOL \\
Observations & 95749 & 94126 & 97199 & 95474 & 89439 & 87081 \\
(\% of non-reponses) & $(6.5)$ & $(8.1)$ & $(5.0)$ & $(6.7)$ & $(12.6)$ & $(14.9)$ \\
Mean & 22.94 & 3.72 & -14.17 & 2.83 & 18.69 & 26.76 \\
Std. Dev. & 54.99 & 60.24 & 50.14 & 50.67 & 49.67 & 47.41 \\
\hline Sources of heterogeneity & across means & of country-year clusters, \% shares & \\
- country effect & 68.0 & 62.0 & 44.6 & 51.2 & 37.9 & 39.2 \\
- time effect & 8.9 & 18.3 & 19.9 & 6.5 & 11.2 & 10.5 \\
- residual effect & 23.1 & 19.7 & 35.5 & 42.3 & 50.9 & 50.3 \\
\hline Sources of heterogeneity & across standard deviations of country-year clusters, \% shares ${ }^{a}$ \\
- country effect & 56.9 & 51.6 & 32.8 & 24.8 & 26.2 & 27.3 \\
- time effect & 4.1 & 6.5 & 10.0 & 13.9 & 12.2 & 19.4 \\
- residual effect & 39.0 & 41.9 & 57.2 & 61.3 & 61.6 & 53.3 \\
\hline
\end{tabular}

${ }^{a}$ The variability between countries and over time is decomposed in three shares: the first (country) is explained by differences across countries, the second (time) by a time-varying drift common to all countries ("time effect"); the residual effect captures idiosyncratic factors.

Table 4. Correlation matrix using all available data ${ }^{a}$

\begin{tabular}{|lcccccc|}
\hline & PASTEC & PASTPOL & PRESEC & PRESPOL & FUTEC & FUTPOL \\
PASTEC & 1 & & & & & \\
PASTPOL & $\mathbf{0 . 6 3 5}$ & 1 & & & & \\
PRESEC & -0.162 & -0.141 & 1 & & & \\
PRESPOL & -0.157 & -0.198 & $\mathbf{0 . 5 3 7}$ & 1 & & \\
FUTEC & -0.145 & -0.173 & $\mathbf{0 . 6 2 2}$ & $\mathbf{0 . 4 7 2}$ & 1 & \\
FUTPOL & -0.149 & -0.193 & $\mathbf{0 . 4 1 9}$ & $\mathbf{0 . 6 8 4}$ & $\mathbf{0 . 6 4 5}$ & 1 \\
\hline
\end{tabular}

a $1 \%$ significant pairwise correlation coefficients are reported in bold. 
Table 5. Principal components analysis by country

\begin{tabular}{lccccccc|}
\hline \multicolumn{1}{|c}{ Eigenvalue: ${ }^{a}$} & $\lambda_{1}$ & $\lambda_{2}$ & $\lambda_{3}$ & $\lambda_{4}$ & $\lambda_{5}$ & $\lambda_{6}$ & $\begin{array}{c}\text { Variation share } \\
\text { explained by } \lambda_{1+} \lambda_{1}{ }^{b}\end{array}$ \\
1. Bulgaria & 2.865 & 1.246 & 0.779 & 0.545 & 0.313 & 0.251 & $\mathbf{0 . 6 8 5}$ \\
2. Czech R. & 3.308 & 1.352 & 0.526 & 0.355 & 0.312 & 0.148 & $\mathbf{0 . 7 7 7}$ \\
3. Slovakia & 3.019 & 1.485 & 0.599 & 0.405 & 0.344 & 0.147 & $\mathbf{0 . 7 5 1}$ \\
4. Hungary & 2.810 & 1.625 & 0.578 & 0.467 & 0.357 & 0.162 & $\mathbf{0 . 7 3 9}$ \\
5. Poland & 3.011 & 1.436 & 0.694 & 0.373 & 0.321 & 0.165 & $\mathbf{0 . 7 4 1}$ \\
6. Romania & 2.500 & 1.519 & 0.872 & 0.499 & 0.387 & 0.223 & $\mathbf{0 . 6 7 0}$ \\
7. Croatia & 2.712 & 1.604 & 0.670 & 0.514 & 0.311 & 0.188 & $\mathbf{0 . 7 1 9}$ \\
8. Slovenia & 2.569 & 1.565 & 0.690 & 0.512 & 0.446 & 0.218 & $\mathbf{0 . 6 8 9}$ \\
9. Belarus & 2.449 & 1.527 & 0.699 & 0.571 & 0.473 & 0.281 & $\mathbf{0 . 6 6 3}$ \\
10. Ukraine & 2.784 & 1.369 & 0.652 & 0.539 & 0.437 & 0.219 & $\mathbf{0 . 6 9 2}$ \\
11. Russia & 2.668 & 1.582 & 0.659 & 0.547 & 0.349 & 0.195 & $\mathbf{0 . 7 0 8}$ \\
12. Estonia & 2.868 & 1.460 & 0.682 & 0.434 & 0.377 & 0.179 & $\mathbf{0 . 7 2 1}$ \\
13. Latvia & 2.813 & 1.475 & 0.734 & 0.439 & 0.387 & 0.152 & $\mathbf{0 . 7 1 5}$ \\
14. Lithuania & 2.864 & 1.382 & 0.659 & 0.489 & 0.433 & 0.172 & $\mathbf{0 . 7 0 8}$ \\
\hline
\end{tabular}

a Ordered eigenvalues of the empirical covariance matrix of the $p=6$ variables of interest.

${ }^{b}$ Cumulative proportion of the overall variation explained by the first two principal components. 
Table 6. Comparison between country averages of $\mathrm{f} 1$ and $\mathrm{f} 2$ before/after $1997^{\mathrm{a}}$

\begin{tabular}{|c|c|c|c|c|c|c|c|c|c|}
\hline & \multicolumn{2}{|l|}{ No. } & \multicolumn{2}{|c|}{ verage of $\mathbf{f 1}$} & \multicolumn{5}{|c|}{ Average of $\mathbf{f} \mathbf{2}$} \\
\hline Code \& country & & $\begin{array}{c}1991- \\
1996\end{array}$ & $\begin{array}{c}1998- \\
2004\end{array}$ & change $^{a}$ & & $\begin{array}{c}1991- \\
1996\end{array}$ & $\begin{array}{r}1998- \\
2004\end{array}$ & change $^{a}$ & \\
\hline 1 Bulgaria & 7148 & -0.013 & 0.016 & 0.029 & & -0.089 & 0.113 & 0.202 & *** \\
\hline 2 Czech R. & 5905 & 0.133 & -0.237 & -0.370 & $* * *$ & -0.004 & 0.007 & 0.011 & \\
\hline 3 Slovakia & 4537 & 0.193 & -0.194 & -0.387 & *** & 0.017 & -0.017 & -0.034 & \\
\hline 4 Hungary & 4681 & -0.180 & 0.231 & 0.411 & *** & 0.010 & -0.013 & -0.024 & \\
\hline 5 Poland & 5237 & -0.068 & 0.109 & 0.177 & *** & -0.079 & 0.127 & 0.205 & *** \\
\hline 6 Romania & 6731 & 0.126 & -0.174 & -0.300 & *** & -0.117 & 0.162 & 0.279 & *** \\
\hline 7 Croatia & 3999 & 0.115 & -0.346 & -0.461 & *** & -0.076 & 0.230 & 0.306 & ${ }^{* * *}$ \\
\hline 8 Slovenia & 6008 & 0.040 & -0.050 & -0.091 & $* * *$ & -0.240 & 0.299 & 0.539 & *** \\
\hline 9 Belarus & 4392 & -0.234 & 0.423 & 0.657 & $* * *$ & 0.069 & -0.124 & -0.193 & *** \\
\hline 10 Ukraine & 4259 & -0.225 & 0.238 & 0.463 & $* * *$ & -0.101 & 0.106 & 0.207 & ${ }^{* * *}$ \\
\hline 11Russia & 15569 & -0.201 & 0.218 & 0.420 & * & -0.165 & 0.179 & 0.344 & *** \\
\hline 12 Estonia & 4503 & -0.104 & 0.147 & 0.251 & $* * *$ & -0.058 & 0.082 & 0.140 & ${ }^{* * *}$ \\
\hline 13 Latvia & 3488 & -0.090 & 0.118 & 0.208 & * & -0.105 & 0.139 & 0.244 & **** \\
\hline 14 Lithuania & 5192 & -0.057 & 0.042 & 0.099 & *** & -0.083 & 0.061 & 0.144 & ${ }^{* * *}$ \\
\hline Total & 81649 & -0.047 & 0.062 & 0.109 & ${ }^{* * *}$ & -0.086 & 0.111 & 0.197 & ${ }^{* * *}$ \\
\hline
\end{tabular}

${ }^{\text {a }}$ Changes which are $1 \%$ significant are marked with $* * *$ on the basis of heteroskedastic-consistent standard errors. 
Table 7. Panel within estimates ${ }^{a}$ of the macro drivers : Factor F1

\begin{tabular}{|c|c|c|c|}
\hline Explanatory variables: & (1) & (2) & (3) \\
\hline $\mathrm{TI}_{\mathrm{c}, \mathrm{t}}^{\mathrm{m}}$ & $\begin{array}{l}-1.86288^{*} \\
(1.118)\end{array}$ & $\begin{array}{r}-0.8416 \\
(0.666)\end{array}$ & \\
\hline $\mathrm{TI}_{\mathrm{c}, \mathrm{t}}^{\mathrm{v}}$ & $\begin{array}{l}1.1611 \\
(1.027)\end{array}$ & $\begin{array}{r}-0.9095 \\
(1.023)\end{array}$ & \\
\hline$U_{c, t}$ & $\begin{array}{l}-0.0310^{* *} \\
(0.015)\end{array}$ & $\begin{array}{r}-0.0198 \\
(0.045)\end{array}$ & \\
\hline$g_{\mathrm{c}, \mathrm{t}}$ & $\begin{array}{l}0.0217^{* * *} \\
(0.007)\end{array}$ & $\begin{array}{l}0.0876^{* * *} \\
(0.032)\end{array}$ & $\begin{array}{l}0.0612^{* *} \\
(0.012)\end{array}$ \\
\hline $\mathrm{TI}_{\mathrm{c}, \mathrm{t}}^{\mathrm{m}} \times g_{\mathrm{c}, \mathrm{t}}$ & & $\begin{array}{l}0.0409 \\
(0.044)\end{array}$ & $\begin{array}{l}0.06122^{* *} \\
(0.012)\end{array}$ \\
\hline $\mathrm{TI}_{c, \mathrm{t}}^{\mathrm{m}} \times u_{\mathrm{c}, \mathrm{t}}$ & & $\begin{array}{r}-0.0053 \\
(0.065)\end{array}$ & $\begin{array}{l}-0.0386 \\
(0.016)\end{array}$ \\
\hline $\mathrm{TI}_{\mathrm{c}, \mathrm{t}}^{\mathrm{v}} \times g_{\mathrm{c}, \mathrm{t}}$ & & $\begin{array}{l}-0.4388^{* * *} \\
(0.096)\end{array}$ & $\begin{array}{l}-0.3854^{* *} \\
(0.088)\end{array}$ \\
\hline$\mu_{\mathrm{c}}^{\mathrm{b}}$ & $\begin{array}{l}1.0988^{* *} \\
(0.417)\end{array}$ & $\begin{array}{l}0.95444^{*} \\
(0.539)\end{array}$ & $\begin{array}{l}0.2697^{* *} \\
(0.109)\end{array}$ \\
\hline$\tau_{t}$ joint significance test ${ }^{c}$ & 0.0010 & no & no \\
\hline R2_adj & 0.3806 & 0.3543 & 0.3614 \\
\hline Std. error of regression & 0.2512 & 0.2548 & 0.2523 \\
\hline No. estimated parameters ${ }^{d}$ & 26 & 21 & 17 \\
\hline F test for restrictions ${ }^{\mathrm{e}}$ & 0.6520 & 0.5648 & 0.4773 \\
\hline
\end{tabular}

Legenda:

${ }^{a}$ Model is specified as unbalanced panel of $\mathrm{N} \times \mathrm{T}$ observations $(\mathrm{N} \times \mathrm{T}=89)$ from 1991 to 2004 for $\mathrm{N}$ countries $(\mathrm{N}=14)$, on average each country belongs to the panel for $T=6.34$ years. OLS estimates with fixed effects (within). White (1980) standard errors robust to heteroskedasticity reported in brackets below coefficient estimates.

${ }^{* * *}=1 \%$ significant, ${ }^{* *}=5 \%$ significant, and ${ }^{*} 10 \%$ significant.

${ }^{\mathrm{b}} \mu_{\mathrm{c}}$ : average of the individual (country) fixed effects.

c When time dummies $\tau_{t}$ are present, the $p$-values of the $F$ test for the joint $\tau_{t}=0$ hypothesis are reported.

${ }^{d}$ Including non-reported estimates of the fixed effects and of the time dummies (if present).

${ }^{\mathrm{e}}$ In each column we report the $\mathrm{p}$-value of the joint parameters restrictions which lead to the specific model of that column. In column (1) restrictions are those imposed on the general model of eq. (4) without interaction terms; in column (2) restrictions are those imposed on the general model of eq. (4) with interactions; in column (3) restrictions are from the model of column (2). 
Table 8. Panel within estimates ${ }^{a}$ of the macro drivers : Factor F2

\begin{tabular}{|c|c|c|c|}
\hline Explanatory variables: & (1) & (2) & (3) \\
\hline $\operatorname{Infl}_{c, t-2}$ & $\begin{array}{l}0.0089 \\
(0.004)\end{array}$ & $\begin{array}{l}0.0000 \\
(0.026)\end{array}$ & \\
\hline$P S_{c, t}$ & $\begin{array}{r}-0.0003 \\
(0.004)\end{array}$ & $\begin{array}{l}0.0031 \\
(0.007)\end{array}$ & \\
\hline Gini $_{c, t-2}$ & $\begin{array}{l}2.1057^{* * *} \\
(0.680)\end{array}$ & $\begin{array}{l}1.6336 \\
(1.300)\end{array}$ & \\
\hline$P S_{c, t} \times\left.\operatorname{lnfl}\right|_{c, t-2}$ & & $\begin{array}{l}0.0176 \\
(0.057)\end{array}$ & $\begin{array}{l}0.0202^{* * *} \\
(0.006)\end{array}$ \\
\hline $\mathrm{PS}_{\mathrm{c}, \mathrm{t}} \times \mathrm{Gini}_{\mathrm{c}, \mathrm{t}-2}$ & & $\begin{array}{l}0.5156 \\
(2.144)\end{array}$ & $\begin{array}{l}2.0629^{* * *} \\
(0.306)\end{array}$ \\
\hline Average $\mu_{\mathrm{c}}{ }^{\mathrm{b}}$ & $\begin{array}{l}-0.8552 \\
(0.220)\end{array}$ & $\begin{array}{c}-0.6769 \\
(0.375)\end{array}$ & $\begin{array}{l}-0.2616^{* * *} \\
(0.052)\end{array}$ \\
\hline$\tau_{t}$ joint significance ${ }^{c}$ & 0.0023 & no & no \\
\hline R2_adj & 0.4419 & 0.3650 & 0.3749 \\
\hline Std. error of regression & 0.1984 & 0.2101 & 0.2078 \\
\hline No. estimated parameters ${ }^{d}$ & 25 & 19 & 16 \\
\hline F test for restrictions ${ }^{e}$ & 0.2540 & 7856 & 0.5373 \\
\hline
\end{tabular}

Legenda: See Table 7. 
Table 9. Test of parameter constancy: excluding one country at a time

\begin{tabular}{|l|cc|}
\hline \multicolumn{1}{|c|}{ Sepecification from: } & $\begin{array}{c}\text { Col (3) of } \\
\text { Table } 7\end{array}$ & $\begin{array}{c}\text { Col (3) of } \\
\text { Table } 8\end{array}$ \\
\hline Excluded Country: & F1 & F2 \\
\hline - Bulgaria & 0.5011 & 0.6918 \\
2 - Czech Republic & 0.9483 & 0.2059 \\
3 - Slovakia & 0.6356 & 0.3176 \\
4 - Hungary & 0.6759 & 0.1641 \\
5 - Poland & 0.2149 & 0.0907 \\
6 - Romania & 0.1556 & 0.9026 \\
7 - Croatia & 0.5384 & 0.3479 \\
8 - Slovenia & 0.6721 & 0.0180 \\
9 - Belarus & 0.2269 & 0.0945 \\
10 - Ukraine & 0.0712 & 0.6277 \\
11 - Russia & 0.3207 & 0.8588 \\
12 - Estonia & 0.7014 & 0.7021 \\
13 - Latvia & 0.8267 & 0.3656 \\
14 - Lithuania & 0.0508 & 0.4958 \\
\hline
\end{tabular}


Table 10. Panel estimates of the macro drivers: whole-sample factor WM1

\begin{tabular}{|c|c|c|c|c|c|c|c|c|}
\hline $\begin{array}{l}\text { Dependent variable: } \\
\text { Explanatory variables: }\end{array}$ & $\begin{array}{l}(1) \\
\text { FM1 }\end{array}$ & & $\begin{array}{c}(2) \\
\text { WM1 }\end{array}$ & & $\begin{array}{c}(3) \\
\text { WM1 }\end{array}$ & & $\begin{array}{c}(4) \\
\text { WM1 }\end{array}$ & \\
\hline \multirow[t]{2}{*}{$g_{c, t}$} & 0.0612 & $* * *$ & 0.0592 & $* * *$ & 0.0584 & $* * *$ & 0.0575 & $* * *$ \\
\hline & 0.0119 & & 0.0119 & & 0.0103 & & 0.0103 & \\
\hline \multirow[t]{2}{*}{$\mathrm{TI}^{\mathrm{m}}{ }_{\mathrm{c}, \mathrm{t}} \times g_{\mathrm{c}, \mathrm{t}}$} & 0.0612 & $* * *$ & 0.0592 & $* * *$ & 0.0584 & $* * *$ & 0.0575 & $* * *$ \\
\hline & 0.0119 & & 0.0119 & & 0.0103 & & 0.0103 & \\
\hline \multirow[t]{2}{*}{$\mathrm{TI}_{\mathrm{c}, \mathrm{t}}^{\mathrm{m}} \times u_{\mathrm{c}, \mathrm{t}}$} & -0.0386 & $* *$ & -0.0369 & $* *$ & -0.0370 & $* * *$ & -0.0343 & $* * *$ \\
\hline & 0.0163 & & 0.0159 & & 0.0102 & & 0.0098 & \\
\hline \multirow[t]{2}{*}{$\mathrm{TI}_{\mathrm{c}, \mathrm{t}}^{\mathrm{v}} \times g_{\mathrm{c}, \mathrm{t}}$} & -0.3854 & $* * *$ & -0.3697 & $* * *$ & -0.3596 & $* * *$ & -0.3556 & $* * *$ \\
\hline & 0.0880 & & 0.0875 & & 0.0758 & & 0.0758 & \\
\hline \multirow[t]{2}{*}{ Rule of Law } & & & & & 0.2220 & $* * *$ & & \\
\hline & & & & & 0.0573 & & & \\
\hline \multirow[t]{2}{*}{ Control of Corruption } & & & & & & & 0.2442 & $* * *$ \\
\hline & & & & & & & 0.0647 & \\
\hline \multirow[t]{2}{*}{ _cons } & 0.1880 & & 0.2925 & $*$ & 0.1876 & $* *$ & 0.1892 & $* *$ \\
\hline & 0.1615 & & 0.1524 & & 0.0757 & & 0.0739 & \\
\hline \multirow[t]{2}{*}{ Bulgaria } & 0.0893 & & 0.0668 & & 0.2060 & $* * *$ & 0.2084 & $* * *$ \\
\hline & 0.1220 & & 0.1138 & & 0.0726 & & 0.0716 & \\
\hline \multirow[t]{2}{*}{ Czech R. } & 0.0123 & & 0.3651 & $* *$ & 0.3043 & $* * *$ & 0.3663 & $* * *$ \\
\hline & 0.1515 & & 0.1419 & & 0.1071 & & 0.1017 & \\
\hline \multirow[t]{2}{*}{ Slovakia } & 0.2022 & & 0.0734 & & - & & - & \\
\hline & 0.1334 & & 0.1285 & & & & & \\
\hline Hungary & - & & - & & - & & - & \\
\hline \multirow[t]{2}{*}{ Poland } & 0.2075 & & 0.2507 & $*$ & 0.2434 & $* * *$ & 0.2378 & $* * *$ \\
\hline & 0.1355 & & 0.1255 & & 0.0883 & & 0.0865 & \\
\hline \multirow[t]{2}{*}{ Romania } & 0.0691 & & -0.0076 & & - & & - & \\
\hline & 0.1626 & & 0.1481 & & & & & \\
\hline \multirow[t]{2}{*}{ Croatia } & 0.0645 & & -0.2194 & & - & & - & \\
\hline & 0.1513 & & 0.1409 & & & & & \\
\hline \multirow[t]{2}{*}{ Slovenia } & 0.0033 & & 0.0872 & & - & & - & \\
\hline & 0.1553 & & 0.1461 & & & & & \\
\hline \multirow[t]{2}{*}{ Belarus } & 0.0485 & & -0.2587 & & - & & - & \\
\hline & 0.1852 & & 0.1708 & & & & & \\
\hline \multirow[t]{2}{*}{ Ukraine } & 0.0765 & & -0.4020 & & - & & - & \\
\hline & 0.2582 & & 0.2680 & & & & & \\
\hline \multirow[t]{2}{*}{ Russia } & 0.0810 & & -0.3592 & $* * *$ & - & & - & \\
\hline & 0.1435 & & 0.1352 & & & & & \\
\hline \multirow[t]{2}{*}{ Estonia } & 0.0359 & & 0.3823 & $* * *$ & 0.3364 & $* * *$ & 0.3153 & $* * *$ \\
\hline & 0.1270 & & 0.1179 & & 0.0740 & & 0.0757 & \\
\hline \multirow[t]{2}{*}{ Latvia } & 0.1403 & & -0.0170 & & - & & - & \\
\hline & 0.1340 & & 0.1244 & & & & & \\
\hline \multirow[t]{2}{*}{ Lithuania } & 0.0998 & & -0.0659 & & - & & - & \\
\hline & 0.1804 & & 0.1768 & & & & & \\
\hline R2_adj & 0.2619 & & 0.6045 & & 0.6086 & & 0.6109 & \\
\hline Std. error of regression & 0.2523 & & 0.2459 & & 0.2446 & & 0.2439 & \\
\hline No. estimated parameters & 17 & & 17 & & 9 & & 9 & \\
\hline $\mathrm{N}$ & 89 & & 89 & & 89 & & 89 & \\
\hline
\end{tabular}

Legenda. Column (1) is identical to Col. (3) of Table 7. Col.(2) is as Col.(1), except for the dependent variable WM1, which factors the same variables as FM1 but on the whole sample instead of by country. Col.(3): indicator of Rule of Law introduced among regressors, non significant country effects deleted. Col.(4): as Col.(3), but indicator of Corruption replaces Rule of Law. Standard errors below coefficient estimates. *, **, *** denote significance at 10\%, 5\%, $1 \%$ resp.

"- indicates country-specific fixed effect restricted to zero, hence country fixed effect is given by the constant term only. Note that R2_adj in col. (1) is not comparable with the other columns, due to different method of estimation. 
Table 11. Panel estimates of the macro drivers: whole-sample factor WM2

\begin{tabular}{|c|c|c|c|c|c|c|c|c|}
\hline $\begin{array}{l}\text { Dependent variable: } \\
\text { Explanatory variables: }\end{array}$ & $\begin{array}{c}\text { (1) } \\
\text { FM2 }\end{array}$ & & $\begin{array}{c}(2) \\
\text { WM2 }\end{array}$ & & $\begin{array}{c}\text { (3) } \\
\text { WM2 }\end{array}$ & & $\begin{array}{c}\text { (4) } \\
\text { WM2 }\end{array}$ & \\
\hline$P S_{c, t} \times\left.\operatorname{lnfl}\right|_{c, t-2}$ & $\begin{array}{l}0.0202 \\
0.0055\end{array}$ & $* * *$ & $\begin{array}{l}0.0173 \\
0.0047\end{array}$ & $* * *$ & $\begin{array}{l}0.0168 \\
0.0047\end{array}$ & $* * *$ & $\begin{array}{l}0.0169 \\
0.0047\end{array}$ & $* * *$ \\
\hline $\mathrm{PS}_{\mathrm{c}, \mathrm{t}} \times \operatorname{Gini}_{\mathrm{c}, \mathrm{t}-2}$ & $\begin{array}{l}2.0629 \\
0.3057\end{array}$ & $* * *$ & $\begin{array}{l}1.9495 \\
0.3004\end{array}$ & $* * *$ & $\begin{array}{l}1.9494 \\
0.2837\end{array}$ & $* * *$ & $\begin{array}{l}1.9559 \\
0.2790\end{array}$ & $* * *$ \\
\hline Mortality Rate & & & & & $\begin{array}{l}0.0012 \\
0.0006\end{array}$ & $* *$ & & \\
\hline Life Expectancy & & & & & & & $\begin{array}{r}-0.0249 \\
0.0118\end{array}$ & $* *$ \\
\hline _cons & $\begin{array}{r}-0.2841 \\
0.0941\end{array}$ & $* * *$ & $\begin{array}{r}-0.1512 \\
0.0872\end{array}$ & $*$ & $\begin{array}{r}-0.4045 \\
0.1178\end{array}$ & $* * *$ & $\begin{array}{l}1.5920 \\
0.8613\end{array}$ & $*$ \\
\hline Bulgaria & $\begin{array}{l}0.0965 \\
0.1147\end{array}$ & & $\begin{array}{l}0.0141 \\
0.1234\end{array}$ & & - & & - & \\
\hline Czech R. & $\begin{array}{r}-0.0839 \\
0.1127\end{array}$ & & $\begin{array}{r}-0.7258 \\
0.1094\end{array}$ & $* * *$ & $\begin{array}{r}-0.6339 \\
0.0967\end{array}$ & $* * *$ & $\begin{array}{r}-0.6339 \\
0.0949\end{array}$ & $* * *$ \\
\hline Slovakia & $\begin{array}{l}0.0130 \\
0.0954\end{array}$ & & $\begin{array}{r}-0.0594 \\
0.0876\end{array}$ & & - & & - & \\
\hline Hungary & - & & - & & - & & - & \\
\hline Poland & $\begin{array}{l}0.0781 \\
0.1285\end{array}$ & & $\begin{array}{r}-0.4208 \\
0.1251\end{array}$ & $* * *$ & $\begin{array}{r}-0.3607 \\
0.1098\end{array}$ & $* * *$ & $\begin{array}{r}-0.3563 \\
0.1094\end{array}$ & $* * *$ \\
\hline Romania & $\begin{array}{l}0.0614 \\
0.1115\end{array}$ & & $\begin{array}{r}-0.3590 \\
0.1082\end{array}$ & $* * *$ & $\begin{array}{r}-0.3204 \\
0.0880\end{array}$ & $* * *$ & $\begin{array}{r}-0.3576 \\
0.0882\end{array}$ & $* * *$ \\
\hline Croatia & $\begin{array}{l}0.0942 \\
0.1431\end{array}$ & & $\begin{array}{r}-0.5214 \\
0.1324\end{array}$ & $* * *$ & $\begin{array}{r}-0.4282 \\
0.1210\end{array}$ & $* * *$ & $\begin{array}{r}-0.4467 \\
0.1171\end{array}$ & $* * *$ \\
\hline Slovenia & $\begin{array}{l}0.0744 \\
0.1333\end{array}$ & & $\begin{array}{r}-0.1671 \\
0.1192\end{array}$ & & - & & - & \\
\hline Belarus & $\begin{array}{l}0.3249 \\
0.1332\end{array}$ & $* *$ & $\begin{array}{l}0.5218 \\
0.1056\end{array}$ & $* * *$ & $\begin{array}{l}0.5043 \\
0.0883\end{array}$ & $* * *$ & $\begin{array}{l}0.4928 \\
0.0904\end{array}$ & $* * *$ \\
\hline Ukraine & $\begin{array}{l}0.0892 \\
0.1265\end{array}$ & & $\begin{array}{l}0.3240 \\
0.1095\end{array}$ & $* * *$ & $\begin{array}{l}0.2851 \\
0.0933\end{array}$ & $* * *$ & $\begin{array}{l}0.2800 \\
0.0938\end{array}$ & $* * *$ \\
\hline Russia & $\begin{array}{r}-0.1172 \\
0.0926\end{array}$ & & $\begin{array}{l}0.0728 \\
0.0842\end{array}$ & & - & & - & \\
\hline Estonia & $\begin{array}{r}-0.1687 \\
0.1032\end{array}$ & & $\begin{array}{r}-0.3064 \\
0.0954\end{array}$ & $* * *$ & $\begin{array}{r}-0.3010 \\
0.0723\end{array}$ & $* * *$ & $\begin{array}{r}-0.3112 \\
0.0714\end{array}$ & $* * *$ \\
\hline Latvia & $\begin{array}{l}0.0598 \\
0.0987\end{array}$ & & $\begin{array}{r}-0.0025 \\
0.0868\end{array}$ & & - & & - & \\
\hline Lithuania & $\begin{array}{r}-0.0885 \\
0.0993 \\
\end{array}$ & & $\begin{array}{l}0.0259 \\
0.0913\end{array}$ & & - & & - & \\
\hline $\begin{array}{c}\text { R2_adj } \\
\text { Std. error of regression }\end{array}$ & $\begin{array}{l}0.3129 \\
0.2078\end{array}$ & & $\begin{array}{l}0.7522 \\
0.2001\end{array}$ & & $\begin{array}{l}0.7619 \\
0.1961\end{array}$ & & $\begin{array}{l}0.7637 \\
0.1954\end{array}$ & \\
\hline No. estimated parameters & 16 & & 16 & & 11 & & 11 & \\
\hline $\mathrm{N}$ & 89 & & 89 & & 89 & & 89 & \\
\hline
\end{tabular}

Legenda. Column (1) is identical to Col. (3) of Table 8. Col.(2) is as Col.(1), except for the dependent variable WM2, which factors the same variables as FM2 but on the whole sample instead of by country.

Col.(3): indicator of Mortality Rate introduced among regressors, non significant country effects deleted. Col.(4): as col.(3), but indicator of Life Expectancy replaces Mortality Rate.

Standard errors below coefficient estimates. $*, * *, * * *$ denote significance at $10 \%, 5 \%, 1 \%$ resp.

"-“" indicates country-specific fixed effect restricted to zero, hence country fixed effect is given by the constant term only. Note that R2_adj in col. (1) is not comparable with the other columns, due to different method of estimation. 


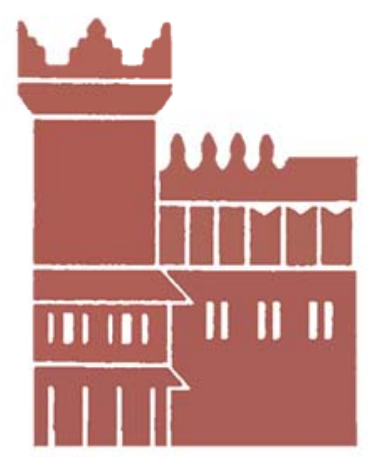

Alma Mater Studiorum - Università di Bologna DEPARTMENT OF ECONOMICS

Strada Maggiore 45

40125 Bologna - Italy

Tel. +39051 2092604

Fax +390512092664

http://www.dse.unibo.it 